\title{
Organisation structurale et moléculaire des lipides dans les aliments : impacts possibles sur leur digestion et leur assimilation par I'Homme
}

\author{
Ketsia RAYNAL-LJUTOVAC ${ }^{1}$ \\ Jérome BOUVIER ${ }^{1}$ \\ Constance GAYET $^{2}$ \\ Noëmie SIMON ${ }^{3}$ \\ Florent JOFFRE ${ }^{4}$ \\ Frédéric FINE ${ }^{5}$ \\ Jean-Luc VENDEUVRE ${ }^{6}$ \\ Christelle LOPEZ $^{7}$ \\ Jean-Michel CHARDIGNY, ${ }^{8,9}$ \\ Marie-Caroline MICHALSKI ${ }^{10}$ \\ Claude GENOT ${ }^{11}$ \\ membres du RMT Listral ${ }^{a}$ \\ ${ }^{1}$ Actilait, \\ Institut technique du lait et des produits \\ laitiers, \\ avenue F. Mitterrand, \\ F-17700 Surgères \\ $<$ k.raynal@actilait.com $>$ \\ 2 Cniel, \\ 42 rue de Châteaudun, \\ F-75314 Paris cedex 9 \\ 3 Onidol, \\ 11 rue de Monceau, \\ F-75008 Paris
}

\footnotetext{
${ }^{a}$ Revue réalisée en hommage à Michel Ollivon (Directeur de Recherche au CNRS, UMR8612, Châtenay-Malabry), décédé en juin 2007, qui a été à l'origine de la création du RMT Listral. Ce Réseau Mixte Technologique avec pour thématique les Lipides Structurés Alimentaires est coordonné par I'ACTIA et animé par Actilait. Les autres partenaires du réseau sont : $F$ Sobolewski \& JP Bodin (Enilia-Ensmic), K Duhem \& JP Guyonnet (Cniel), JP Bergé \& JP Gouygou (Ifremer Nantes), G Nassy (Ifip), Lebois \& D Majou (Actia), P Gaborit \& R Richoux (Actilait).
}

\begin{abstract}
From the nutrition point of view, lipids are primarily considered as energy suppliers, their dietary intake having to be limited. In fact, lipids are sources of various fatty acids, and dietary recommendations include the required daily intakes in different fatty acids (fatty acid profile). Beyond these quantitative aspects, fatty acids are part of larger molecules, mainly triacylglycerols (TAG), that are organized in supramolecular structures as for example fat crystals and lipid droplets. Recent advances in nutrition research have demonstrated that these structures, and lipid organization in food matrices, influence digestibility and metabolism of fatty acids. Therefore, the members of the technological network Listral propose a synthesis of the knowledge about the influence of molecular and supramolecular structures of lipids on digestion and metabolic fate of dietary fatty acids originating from for the main food industry sectors. Fatty acids are mainly provided in the diet in the form of TAG, or phospholipids (PL) where they are esterified in external (sn-1, sn-3) or internal (sn-2) position of the glycerol backbone. They can also be found as ethyl esters (EE) in specific formulations. These molecular characteristics of the lipid molecules affect their hydrolysis and their absorption rate but also their metabolism in indifferent organs, as assessed in studies often using inter esterified fat sources. The results depend on the types of fatty acids (saturated or polyunsaturated fatty acids) but also on the model used for the studies: in vitro or in vivo studies; animal model, human newborn or adult, either healthy or exhibiting some diseases. Among others, it was found that the crystal form and fat melting point as affected by the fatty acid profiles and the lipid molecular structures directly impact fatty acid absorption kinetics through modifications of lipolytic enzyme activities. However, in these studies, the relative effect of the thermal properties of lipids and the proportion of saturated fatty acids chains in sn-2 position were hardly distinguished. Supramolecular structures, namely type and size of the fat droplets and their interfacial composition, of lipids, either in their native forms or obtained after food processes, also affect the digestibility and absorption of lipids. This aspect is reviewed with specific focus on dairy, marine, meat, oil plant and egg products. The impact of other nutritional components present in these food matrices on the absorption of lipids is also discussed.
\end{abstract}

Key words: fatty acid, triacylglycerol, phospholipid, crystallisation, lipid metabolism, functional properties, milk, egg, meat, fish, vegetal oil

Pour citer cet article : Raynal-Ljutovac K, Bouvier J, Gayet C, Simon N, Joffre F, Fine F, Vendeuvre JL, Lopez C, Chardigny JM, Michalski MC, Genot C. Organisation structurale et moléculaire des lipides dans les aliments : impacts possibles sur leur digestion et leur assimilation par l'Homme. OCL 2011 ; 18(6) : 324-351. doi : 10.1684/ocl.2011.0415 
4 Iterg,

11 rue Monge,

F-33600 Pessac

${ }^{5}$ Cetiom,

11 rue Monge,

F-33600 Pessac

6 Ifip,

7 av Gal de Gaulle,

F-94700 Maisons Alfort

7 Inra STLO,

65 rue de St Brieuc,

F-35042 Rennes

${ }^{8}$ Clermont Université,

Université d'Auvergne,

CRNH Auvergne,

Unité de Nutrition Humaine,

BP 10448,

F-63000 Clermont-Ferrand

9 Inra,

UMR 1019,

UNH,

F-63009 Clermont-Ferrand

10 Inra USC1235,

Inserm U1060,

CarMeN - IMBL,

Insa-Lyon,

11 avenue Jean Capelle, F- 69621

Villeurbanne cedex

11 Inra,

UR1268 Biopolymères Interactions

Assemblages,

BP71627,

F-44316 Nantes

\section{Introduction}

Selon I'avis récent de I'ANSES (Afssa, 2010), les lipides alimentaires devraient représenter 35 à $40 \%$ de l'apport énergétique total, soit environ $20 \%$ en masse de l'ensemble des macronutriments (protéines + glucides + lipides). Cet apport quantitatif de matière grasse provient de multiples sources alimentaires. Ainsi, le nombre d'industries alimentaires françaises directement concernées par la filière matière grasse est important avec notamment 300 millions de litres d'huiles consommées en 2010 et environ 1 million de tonnes de matières grasses laitières consommées sous toutes leurs formes en 2008 (Agreste, 2010), auxquels il faut ajouter tous les aliments bruts ou transformés dans lesquels les lipides sont une composante importante des qualités techno-fonctionnelles, sensorielles et nutritionnelles. Cette composante énergétique de l'apport lipidique alimentaire ne doit cependant pas faire oublier que bon nombre de constituants lipidiques sont vitaux car ils entrent dans la constitution de nos cellules ou contribuent à leur métabolisme. Comme le souligne I'avis de I'ANSES, la composition en acides gras est le premier facteur conditionnant la qualité nutritionnelle des lipides alimentaires (acides gras insaturés vs. saturés, longs vs courts ou moyens, $\varpi 3$ vs $\varpi 6 . .$.$) .$

Les avancées de la recherche en nutrition de ces dernières années ont permis de mettre en évidence que la structuration moléculaire et supramoléculaire de la matière grasse dans les matrices alimentaires module sa digestion et le devenir métabolique des acides gras. En effet, l'ancrage des acides gras sur les triglycérides ou les phospholipides, I'agencement de ces molécules sous forme d'émulsions de gouttelettes lipidiques de tailles et de compositions interfaciales variables et enfin la quantité de matière grasse cristallisée influencent leur digestibilité et leur métabolisme. Ceci pourrait modifier par voie de conséquence leur impact physiopathologique. Cet article dresse l'état des lieux des connaissances actuelles sur ce sujet.

\section{Les structures des lipides; de la molécule à I'aliment}

\section{Les principaux acides gras alimentaires}

Les lipides sont définis comme étant les acides gras (AG), leurs dérivés et les substances qui leur sont apparentées du point devue deleurbiosynthèse ou deleur fonctionnalité (Christie-Lipidlibrary.aocs. org). Ils sont caractérisés par la présence d'au moins une chaîne hydrocarbonée et peuvent contenir azote, phosphore et soufre. Ils constituent ainsi un ensemble très hétérogène de molécules organiques en général insolubles ou partiellement solubles dans l'eau et solubles dans les solvants organiques apolaires.

Les acides gras, qui sont le motif structural de base des lipides, sont caractérisés par :

- leur longueur de chaîne : la grande majorité des AG naturels sont constitués d'une chaîne linéaire à nombre pair de carbones allant de 4 à 24 carbones; les
AG de 16 à 22 carbones étant les plus représentés parmi les lipides alimentaires ;

- leur degré d'insaturation ( 0 à 6 doubles liaisons) avec des doubles liaisons majoritairement en configuration cis et non conjuguées. La présence de configurations trans dans certaines matières grasses modifie la conformation dans l'espace de la molécule et ses propriétés. La position de la double liaison terminale (la plus proche du $\mathrm{CH}_{3}$ terminal) définit la classification des acides gras insaturés en acides gras des séries n-9 (oméga-9 : $\varpi 9$ ), n-6 (oméga-6 : ఐ6) ou n-3 (oméga-3 : $\varpi 3$ ).

Quelques compositions en acides gras de produits alimentaires sont données dans le tableau 1 à titre indicatif mais une très grande variabilité est observée pour les végétaux selon les espèces et les variétés et pour les animaux, selon les espèces, les modes d'alimentation (Bourre, 2003), le stade physiologique, I'adiposité et la localisation de la matière grasse tissulaire dans la carcasse.

\section{Les acides gras dans}

\section{les structures moléculaires}

Les acides gras non estérifiés, ou acides gras libres (AGL), sont présents à faibles concentrations (quelques pour cent au maximum) dans les lipides alimentaires. Ils sont généralement considérés comme des marqueurs d'une dégradation de la matière première ou du produit fini au cours des étapes de transformation ou de stockage. Leur production par les lipases endogènes tissulaires ou exogènes microbiennes peut être recherchée, notamment dans le cas de certains fromages et de saucissons crus fermentés séchés.

L'essentiel des apports lipidiques alimentaires (80 à $120 \mathrm{~g} /$ jour en moyenne) est constitué de triesters d'AG et de glycérol: les triglycérides ou triacylglycérols (TAG). Ce sont les constituants très majoritaires des huiles et matières grasses alimentaires. Une huile est ainsi caractérisée non seulement par sa composition globale en AG, mais aussi par sa composition en espèces moléculaires, chaque espèce moléculaire se définissant par la nature des AG estérifiés en position externe : sn-1 ou sn-3, ou interne (sn-2) du glycérol (figure 1-1A). Par exemple, dans le saindoux, l'acide palmitique est majoritairement en position sn-2, contrairement au suif (tableau 2). L'huile de soja et le beurre 
Tableau 1. Exemples de composition en classes d'acides gras (\% des acides gras totaux) de quelques aliments (sujet à variation en fonction des races, espèces animales, saison, âge et alimentation de l'animal...).

\begin{tabular}{|c|c|c|c|c|}
\hline & $\begin{array}{l}\text { Acides gras } \\
\text { principaux }\end{array}$ & $\begin{array}{l}\text { \% Acides gras } \\
\text { saturés }\end{array}$ & $\begin{array}{l}\text { \% Acides gras } \\
\text { mono-insaturés }\end{array}$ & $\begin{array}{l}\% \text { Acides gras } \\
\text { polyinsaturés }\end{array}$ \\
\hline Lait (beurre) ${ }^{2}$ & $\begin{array}{l}\text { C16:0 (22-42 \%) } \\
\text { C18:1 n-9 }(18-34 \%)^{1}\end{array}$ & 67 & 30 & 3 \\
\hline (Euf (jaune) $^{3}$ & $\begin{array}{l}\text { C18:1 n-9 }(31-42 \%)^{4} \\
\text { C16:0 }(22 \%)^{4}\end{array}$ & 38 & 46 & 16 \\
\hline Bœuf (suif) ${ }^{2}$ & $\begin{array}{l}\text { C18:1 n-9 (37 \%) } \\
\text { C16:0 (26 \%) }\end{array}$ & 57 & 41 & 2 \\
\hline Porc (saindoux) ${ }^{2}$ & $\begin{array}{l}\text { C18:1 n-9 (44 \%) } \\
\text { C16:0 (25 \%) }\end{array}$ & 43 & 48 & 9 \\
\hline $\begin{array}{l}\text { Volaille } \\
\text { (graisse de poulet) }^{2}\end{array}$ & $\begin{array}{l}\text { C18:1 n-9 (40 \%) } \\
\text { C16:0 (22 \%) }\end{array}$ & 31 & 47 & 22 \\
\hline Huile de foie de morue ${ }^{2}$ & $\begin{array}{l}\text { C18:1 n-9 (21 \%) } \\
\text { C20:1 (19 \%) }\end{array}$ & 16 & 54 & 25 \\
\hline $\begin{array}{l}\text { Poisson gras } \\
\text { (huile hareng) }^{2}\end{array}$ & $\begin{array}{l}\text { C22:1 (23 \%) } \\
\text { C20:1 (18 \%) }\end{array}$ & 21 & 62 & 17 \\
\hline Huile d'olive ${ }^{3}$ & C18:1 n-9 (55-83 \%) & 15 & 77 & 8 \\
\hline Huile de colza ${ }^{3}$ & C18:1 n-9 (55-62 \%) & 7 & 62 & 31 \\
\hline Huile de $\operatorname{lin}^{6}$ & C18:3 n-3 (56-71\%) & 9 & 17 & 74 \\
\hline Huile de tournesol ${ }^{3}$ & C18:2 n-6 (62-70 \%) & 12 & 21 & 67 \\
\hline Huile de tournesol oléique ${ }^{6}$ & C18:1 n-9 (75-85 \%) & 8 & 82 & 10 \\
\hline Huile de soja ${ }^{3}$ & $\begin{array}{l}\text { C18:2 n-6 (48-59 \%) } \\
\text { C18:1 n-9 }(17-30 \%)^{5}\end{array}$ & 15 & 22 & 63 \\
\hline Graisse de palme ${ }^{6}$ & $\begin{array}{l}\text { C16:0 }(39-47 \%)^{5} \\
\text { C18:1 n-9 }(36-44)^{5}\end{array}$ & 50 & 40 & 10 \\
\hline Beurre de cacao $^{6}$ & $\begin{array}{l}\text { C18:0 (30-37 \%) } \\
\text { C18:1 n-9 (33-39 \%) }\end{array}$ & 62 & 35 & 3 \\
\hline
\end{tabular}

${ }^{1}$ Gnädig et al. (2001).

${ }^{2}$ Répertoire général des aliments. Table de composition des corps gras

${ }^{3}$ Table de composition CIQUAL (http://www.afssa.fr/Table)

${ }^{4}$ Pieroni et Coste (2010)

${ }^{5}$ Codex Alimentarius, Norme Codex Stan 210

${ }^{6}$ Iterg

de cacao contiennent également des AG saturés préférentiellement en position externe et des AG insaturés (oléique, linoléique...) en position sn-2 alors que I'acide oléique est majoritairement en position externe dans le saindoux (Hunter, 2001). Le taux de répartition de l'acide $\alpha$-linolénique (tableau 3) sur la position sn-2 est de $58 \%$ dans I'huile de colza, contre $32 \%$ dans I'huile de noix et $31 \%$ dans I'huile de soja (Combe et BoueVaysse, 2004). Les triacylglycérols de l'œuf sont quant à eux caractérisés par une localisation préférentielle de I'acide palmitique en position sn- 1 du glycérol, tandis que l'acide oléique se partage de façon équivalente entre les positions sn-2 et sn-3 (Kuksis, 1992). Les AG polyinsaturés (AGPI) occupent préférentiellement la position sn-2 (Schreiner et al., 2004). Enfin, contrairement à I'huile de poisson, les huiles de mammifères marins comme la baleine et le phoque sont composées de TAG dont les AGPI à longues chaînes, acides eicosapentaenoique (EPA ; 20:5 n-3) et docosahexaénoïque (DHA; 22:6 n-3), sont principalement localisés en positions externes (Ackman, 1988).

Une autre classe de lipides, importante pour ses fonctionnalités technologiques et nutritionnelles, est celle des lipides polaires : phospholipides (PL), glycolipides et sphingolipides cellulaires (lipides membranaires). Ils s'opposent ainsi aux lipides neutres (TAG), monoacylglycérides (MAG) et diacyglycérides (DAG). Les lipides polaires représentent
1 à $10 \%$ des apports en lipides dans I'alimentation. Ils proviennent essentiellement des œufs, de la viande, du poisson et du lait mais également des lécithines de soja utilisées comme ingrédient techno-fonctionnel (grâce à ses propriétés émulsifiantes) dans de nombreux secteurs alimentaires (desserts, viennoiseries, chocolats, plats préparés...). Dans le cas des phospholipides (glycérophospholipides, couramment appelés lécithines en technologie; exemple figure 1-10), la fonction alcool du glycérol en position sn-3 est estérifiée par un groupement phosphoryle luimême substitué par un groupement polaire, chargé (phosphatidyl-sérine, phosphatidyl-inositol, etc.) ou non (phosphatidyl-choline, phosphatidyléthanolamine). Sur les deux autres 
1) Échelle moléculaire

A : triacylglycérol (TAG)

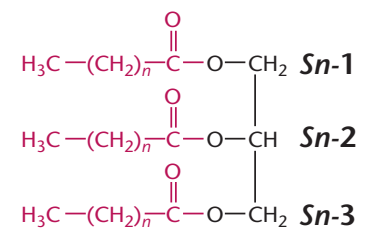

C : glycérophospholipides<smiles>[X]OP(=O)(O)OC([18OH])C(COC(=O)CCC)OC(=O)CC</smiles>

$\mathrm{X}=$ éthanolamine, choline, sérine, inositol
B : sn-2 monoacylglycérol (2-MAG)

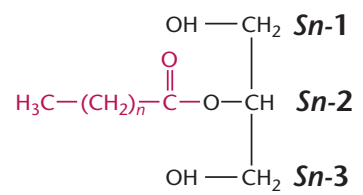

D : sn-2 lysophospholipides<smiles>[X]OP(=O)([O-])OC([Hg])C(O)COC(=O)CCC</smiles>

$X$ = éthanolamine, choline, sérine, inositol

2) Échelle supramoléculaire

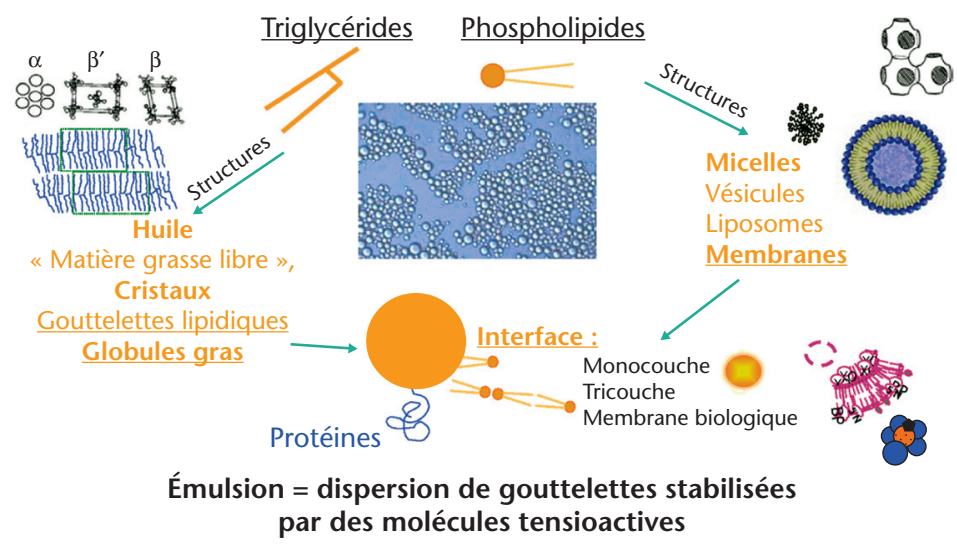

3) Échelle macroscopique

- Phase continue lipidique :

- Matière grasse libre : huile et saindoux

- Emulsion eau/huile : beurre, margarine

- Particules dans MG solide : chocolat

- Phase continue aqueuse :

- Emulsion huile/eau : sauce, lait

- Gouttelettes lipidiques intracellulaires

et structures membranaires (tissus) :

viande, jaune d'œuf, végetaux

- Structure solide complexe :

- Insertions lipidiques dans matrice

glucidique ou protéique :

produits élaborés (biscuits, fromages)
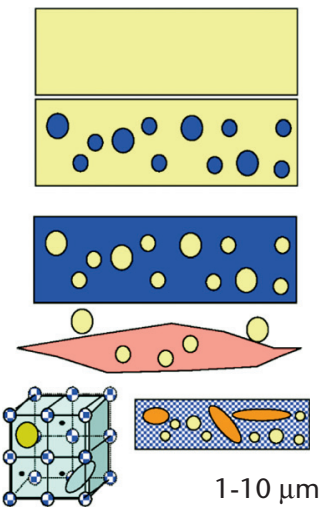

Figure 1. Organisation multi-échelle des lipides dans les aliments : du moléculaire au macroscopique. Adapté de Genot et Michalski (2010). 
Tableau 2. Répartition des principaux acides gras sur les 3 positions des TAG de différentes matières grasses alimentaires; adapté des revues de Berry (2009), Michalski (2008, 2009) et CTSCCV-ACTIA (2001).

\begin{tabular}{|c|c|c|c|c|c|c|c|}
\hline \multirow[b]{2}{*}{$\begin{array}{l}\text { Matières grasses } \\
\text { (espèces de TAG } \\
\text { majoritaires) }\end{array}$} & \multirow[b]{2}{*}{$\begin{array}{l}\text { Position sn } \\
\text { sur le TAG }\end{array}$} & \multicolumn{6}{|c|}{$\begin{array}{l}\text { Localisation des principaux acides gras } \\
\text { (\% de I'acide gras sur chaque position sn = mole de I'acide gras sur la position sn } \\
\text { considérée pour } 100 \text { mol de cet acide gras dans I'ensemble des TAG de cette } \\
\text { matière grasse) }\end{array}$} \\
\hline & & $\begin{array}{l}\text { Acides } \\
\text { gras courts } \\
\text { et moyens } \\
(\text { C4:0 à } C 12: 0)\end{array}$ & $\begin{array}{l}\text { Acide } \\
\text { palmitique } \\
(C 16: 0)\end{array}$ & $\begin{array}{l}\text { Acide } \\
\text { stéarique } \\
(\mathbf{C 1 8 : 0 )}\end{array}$ & $\begin{array}{l}\text { Acide } \\
\text { oléique } \\
(\text { C18:1 n-9) }\end{array}$ & $\begin{array}{l}\text { Acide } \\
\text { linoléique } \\
(\text { C18:2 n-6) }\end{array}$ & $\begin{array}{l}\text { Acide } \\
\text { alpha- } \\
\text { linolénique } \\
(\text { C18:3 n-3) }\end{array}$ \\
\hline \multirow{4}{*}{$\begin{array}{l}\text { Beurre de cacao } \\
\text { (POS, SOS, POP) }\end{array}$} & $\%$ des AG totaux & - & 27 & 35 & 34 & 3 & 0,1 \\
\hline & sn-1 & - & 47 & 48 & 11 & 10 & ns \\
\hline & sn-2 & - & 3 & 2 & 81 & 90 & ns \\
\hline & sn-3 & - & 51 & 50 & 8 & Traces & ns \\
\hline \multirow{4}{*}{$\begin{array}{l}\text { Huile de palme } \\
\text { (POP, POO, POL) }\end{array}$} & $\%$ des AG totaux & 0,1 & 43 & 6 & 39 & 10 & 0,3 \\
\hline & sn-1 & & 41 & 27 & 25 & 30 & ns \\
\hline & sn-2 & C12:0:17 & 9 & Traces & 62 & 60 & ns \\
\hline & sn-3 & & 50 & 73 & 13 & 10 & ns \\
\hline \multirow{4}{*}{$\begin{array}{l}\text { Huile d'arachide } \\
\text { (OOL, POL, OLL) }\end{array}$} & $\%$ des AG totaux & & 10 & 3 & 55 & 27 & ns \\
\hline & sn-1 & - & 52 & 50 & 34 & 28 & ns \\
\hline & sn-2 & - & 7 & Traces & 34 & 57 & ns \\
\hline & sn-3 & - & 41 & 50 & 33 & 15 & ns \\
\hline \multirow{4}{*}{$\begin{array}{l}\text { Beurre } \\
\text { (OPBu, PPBu, PMyBu) }\end{array}$} & $\%$ des AG totaux & 14 & 26 & 11 & 25 & 2 & 1 \\
\hline & sn-1 & & 44,5 & 56 & 59 & & \\
\hline & sn-2 & $\begin{array}{l}C 8: 0: 43,5 \\
C 10: 0: 51,5 \\
C 12: 0: 60\end{array}$ & 43 & 16 & 0 & 35 & 44 \\
\hline & sn-3 & $\begin{array}{l}C 4: 0+C 6: 0>93 \\
C 8: 0: 52,5\end{array}$ & 12,5 & 28 & 41 & & \\
\hline \multirow{4}{*}{$\begin{array}{l}\text { Saindoux } \\
\text { (SPO, OPL, OPO) }\end{array}$} & $\%$ des AG totaux & 0,1 & 25 & 15 & 44 & 9 & 0,6 \\
\hline & sn-1 & C12:0:ns & 23 & 54 & 43 & 35 & ns \\
\hline & sn-2 & C12:0 :ns & 61 & 8 & 13 & 26 & ns \\
\hline & sn-3 & C12:0 :ns & 16 & 38 & 44 & 39 & ns \\
\hline \multirow{4}{*}{$\begin{array}{l}\text { Suif } \\
\text { (POO, POP, PSO) }\end{array}$} & $\%$ des AG totaux & 0,1 & 26 & 23 & 37 & 1,5 & 0,6 \\
\hline & sn-1 & C12:0 :ns & 51 & 34 & 20 & 29 & ns \\
\hline & sn-2 & C12:0 :ns & 21 & 18 & 42 & 36 & ns \\
\hline & sn-3 & C12:0:ns & 28 & 48 & 38 & 36 & ns \\
\hline \multirow{4}{*}{$\begin{array}{l}\text { Huile de soja }{ }^{2} \\
\text { (OLL, LLL, PLL) }\end{array}$} & $\%$ des AG totaux & - & 10 & 4 & 23 & 54 & 8 \\
\hline & sn-1 & & 50 & 48 & 32 & 29 & 37 \\
\hline & sn-2 & & 4 & 4 & 29 & 43 & 29 \\
\hline & sn-3 & & 46 & 48 & 39 & 28 & 33 \\
\hline \multirow{3}{*}{$\begin{array}{l}\text { Huile de tournesol } \\
\text { (LLL, OLL, PLL) }\end{array}$} & $\%$ des AG totaux & - & 7 & 4 & 23 & 65 & ns \\
\hline & sn-1,3 & & 66 & 65 & 50 & 47 & ns \\
\hline & sn-2 & & 34 & 35 & 50 & 53 & \\
\hline \multirow{3}{*}{$\begin{array}{l}\text { Huile de colza }{ }^{2} \\
\text { (OOO, OOL, } \\
\text { OLL, OOLn) }\end{array}$} & $\%$ des AG totaux & - & 4 & 2 & 62 & 21 & 9 \\
\hline & sn-1,3 & & 83 & 80 & 54 & 36 & 33 \\
\hline & sn-2 & & 17 & 20 & 46 & 64 & 67 \\
\hline
\end{tabular}

Cases vides : complément à 100 pour l'acide gras indiqué (par exemple dans l'huile de palme, 83 \% du C12:0 est situé en positions externes sn-1/3).

ns : répartition non spécifiée (acide gras minoritaire dans le profil en acides gras totaux).

- : acide gras absent de cette matière grasse.

Bu : acide Butyrique, L : acide linoléique C18:2, Ln : acide alpha-linolénique C18:3, My : acide myristique, $\mathrm{O}$ : acide oléique C18:1, P : acide palmitique C16:0, S : acide stéarique C18:0.

$\%$ AG totaux selon le Répertoire général des aliments (table de composition des corps gras, CIQUAL)

${ }^{1}$ Source Lesieur.

${ }^{2}$ Données Iterg, adaptées de The Lipid Handbook, 2007, $3^{\text {rd }}$ edition, Ed. Gunstone FD, Harwood JL, Dijkstra AJ - CRC Press \& Manuel des Corps gras, 1992, Ed. Karleskind/AFECG, Lavoisier Tec\&Doc. 
Tableau 3. Composition (\% en poids) en acides gras de trois huiles « linoléniques " et taux de répartition de l'acide alpha-linolénique en position sn-2 (Combe et Boue-Vaysse, 2004).

\begin{tabular}{|c|c|c|c|}
\hline & Colza & Noix & Soja \\
\hline Acide palmitique $\mathrm{C} 16: 0$ & $1-5$ & $6-8$ & $8-13$ \\
\hline Acide stéarique C18:0 & $1-2$ & $1-3$ & $2-5$ \\
\hline Acides gras saturés & $2-8$ & $7-11$ & $12-20$ \\
\hline Acide oléique C18:1 n-9 & $55-62$ & $14-21$ & $17-26$ \\
\hline Acide érucique C22:1 n-9 & $<1$ & - & - \\
\hline Acides gras mono-insaturés & $56-65$ & $14-21$ & $18-27$ \\
\hline Acide linoléique C18:2 n-6 & $18-22$ & $54-65$ & $50-62$ \\
\hline Acide linolénique C18:3 n-3 & $8-10$ & $9-15$ & $4-10$ \\
\hline * Taux de répartition (\%) en position sn2 du C18:3 n-3 & 58 & 32 & 31 \\
\hline Acides gras polyinsaturés & $26-32$ & $63-80$ & $54-72$ \\
\hline C18:2 n-6/C18:3n-3 & $2-3$ & $4-7$ & $10-15$ \\
\hline
\end{tabular}

* Le complément à 100 représente les proportions de C18:3 n-3 estérifiées sur les positions externes du glycérol (sn-1 + sn-3)

fonctions alcool sont fixés soit un (on parle de lysophospholipide; figure 1 $1 D$ ), soit deux acides gras. Généralement dans les PL naturels, au moins une chaîne d'acide gras est insaturée, le plus souvent en position sn-2. Des sphingolipides, dans lesquels les acides gras sont fixés sur la sphingosine, sont également présents dans les membranes des cellules des mammifères, et en particulier dans les tissus nerveux. La sphingomyéline est également présente dans la membrane entourant les globules gras du lait. Les glycolipides dont la partie polaire contient une chaîne glucidique (un à deux galactoses le plus généralement) sont également assez abondants dans les matières premières végétales.

Dans les produits alimentaires n'ayant pas subi de transformation, ces structures moléculaires de TAG et de lipides polaires sont organisées (figure 1-2 et 1-3) sous forme de structures supramoléculaires natives telles que les globules gras du lait (figure 2), les adipocytes dans la viande et le poisson (figure 3), les lipoprotéines du jaune d'œuf (figure 4), et les oléosomes des graines oléagineuses (figure 5).

Les procédés de transformation affectent ces structures natives et modifient leurs propriétés techno-fonctionnelles voire nutritionnelles. La digestion des lipides et leur assimilation par l'organisme en fonction de leur structuration sont des processus complexes qui sont loin d'être élucidés.

\section{La structure moléculaire de I'apport lipidique modifie-t-elle les effets biologiques des acides gras?}

Selon que les acides gras sont apportés sous forme d'esters éthyliques (EE), de

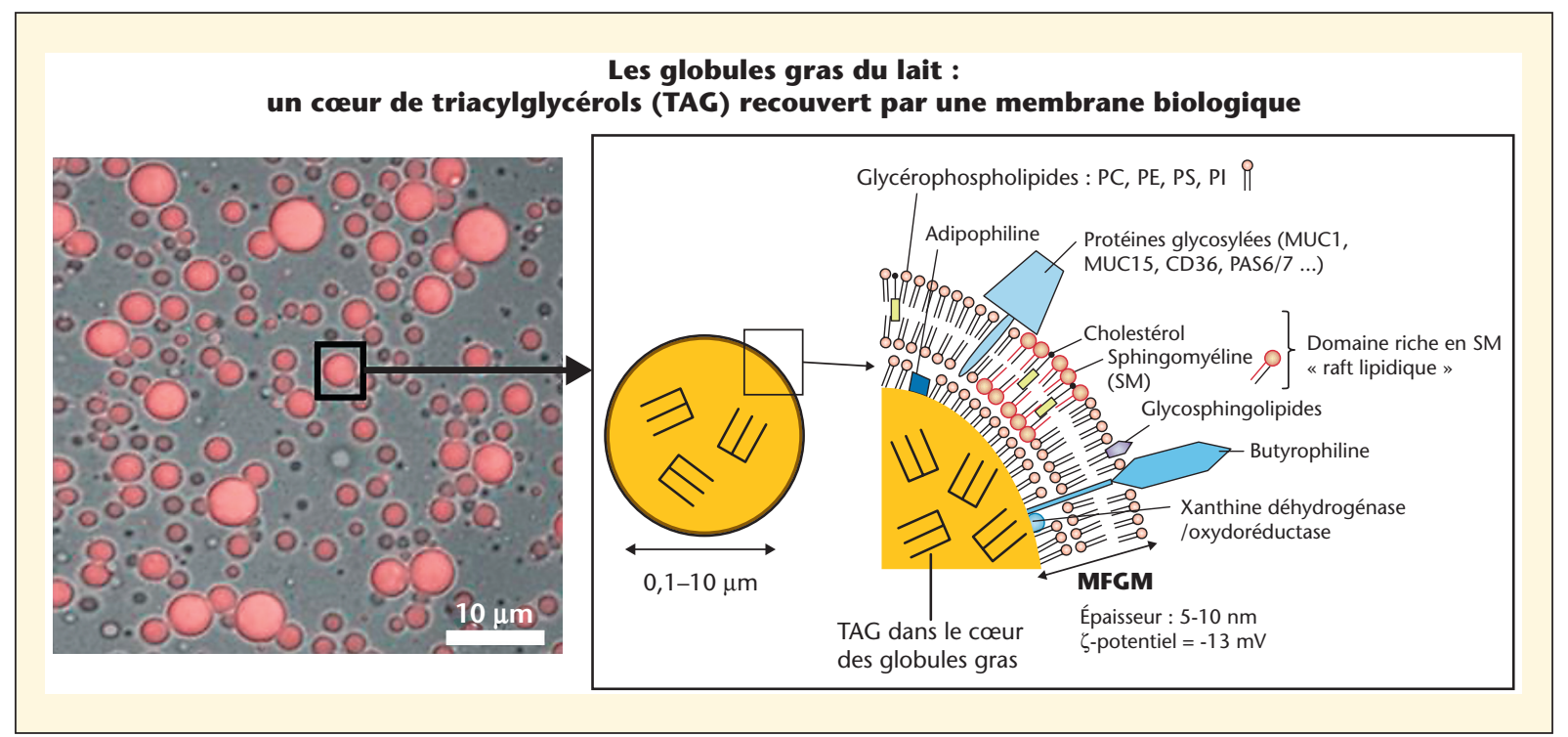

Figure 2. Organisation des lipides du lait : le globule gras. Adapté de Lopez et al., 2010. 


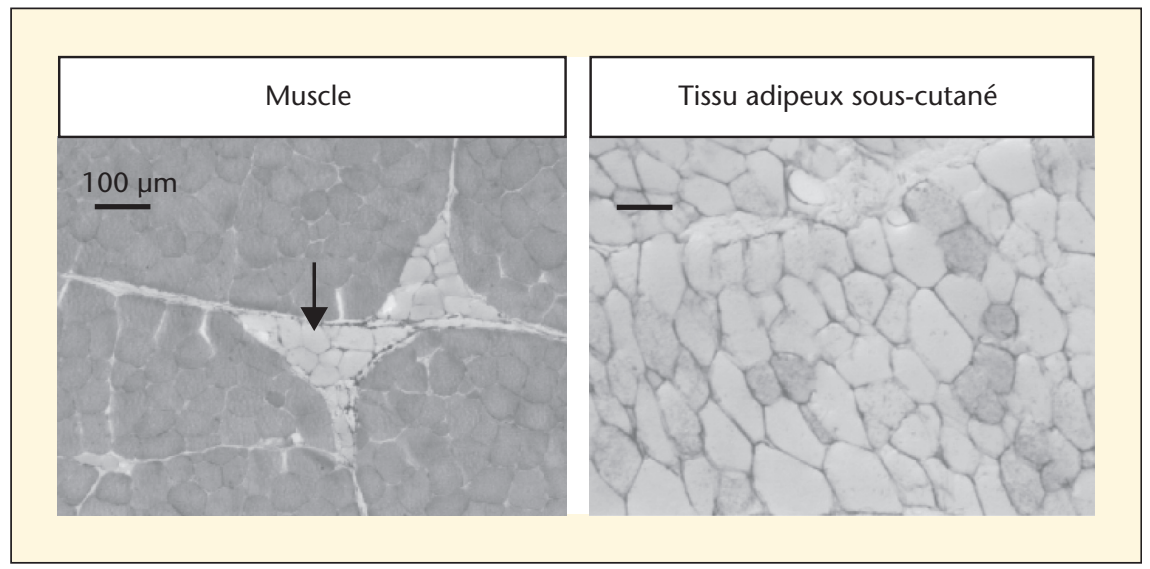

Figure 3. Organisation des lipides intramusculaires et de dépôt dans les tissus animaux: exemple de l'adipocyte de porc (porc à $100 \mathrm{~kg}$ de poids vif). Illustration de Gondret F, Inra Phase, Saint Gilles.

TAG ou de $\mathrm{PL}$, selon qu'ils sont ancrés en position externe (sn-1, sn-3) ou interne (sn-2) de ces deux molécules, leur hydrolyse, leur vitesse d'absorption mais également leur impact sur les organes cibles diffèrent.

\section{Impact de la structure intramoléculaire des TAG sur I'absorption des acides gras}

De nombreux travaux ont été réalisés afin d'étudier la digestion, l'absorption et le métabolisme des acides gras alimentaires en fonction de la structure intramoléculaire des TAG. En effet, $97 \%$ des acides gras de notre alimentation sont apportés sous cette forme. La figure 6 synthétise le processus de digestion des lipides et plus particulièrement des TAG. Des revues très détaillées ont été publiées sur ce sujet (Berry et Sanders, 2005 ; Berry, 2009 ; Bracco, 1994 ; Hunter, 2001 ; Ikeda, 2000 ; Mu et Hoy, 2004 ; Mu et Porsgaard, 2005 ; Ramirez et al., 2001 ; Sala-Vila et al., 2008 ; Small, 1991). Des résultats divergents ont parfois été obtenus mais ils pourraient être expliqués par les différents modèles d'étude utilisés, les différentes espèces moléculaires de TAG ainsi que leur pureté et la présence d'autres composants non lipidiques dans le régime alimentaire.

Il paraît désormais admis que la structure intramoléculaire des TAG influe sur les cinétiques $d$ 'hydrolyse des acides gras notamment de par l'action spécifique des enzymes digestives. En effet, les lipases digestives hydrolysent avec une plus grande spécificité les AG à courte chaîne et les acides gras estérifiés en positions externes sn- 1 et sn-3 par rapport à la position interne sn-2 des TAG (Hamosh, 1990 ; Hamosh et al., 1985 ; Abrams et al., 1987 ; Gargouri et al., 1986 ; Moreau et al., 1988). La lipase pancréatique présente une faible activité vis-à-vis de TAG comportant des AGPI avec un nombre de doubles liaisons cis supérieur à 4 du fait de l'encombrement stérique engendré par la présence de ces doubles liaisons (Carrière, 2008), notamment lorsqu'ils sont en position externe (Porsgaard et al., 2005 ; Christensen et al., 1994 ; Christensen et Høy, 1996 ; Straarup et Høy, 2001). Ceci va dans le sens des observations de Bottino et al. (1967) qui ont montré in vitro que le DHA et I'EPA de l'huile de baleine étaient plus résistants aux lipases pancréatiques que les autres acides gras (principalement $\mathrm{C} 16: 0$ et $\mathrm{C} 18: 1 \mathrm{n}-9$ ) en raison de contraintes stériques liées à la double liaison proche du groupe carboxyle, indépendamment de leur position sur le TAG.

Par ailleurs, il a été montré que la position des AG sur le glycérol détermine le point de fusion des TAG (Small, 1991). Pour une même composition en $A G$, la structure intramoléculaire des TAG peut donc affecter le pourcentage de lipides solides à la température physiologique de la digestion, c'est-à-dire $37^{\circ} \mathrm{C}$, ainsi que l'action des enzymes digestives. Cet aspect est détaillé dans la section Influence de l'organisation de la matiere grasse dans I'aliment de cette revue.

Après action des lipases digestives, en période postprandiale, les 2-monoacyl- glycérol (2-MAG ; figure 1.1B) et les AGL issus des positions sn- 1 et sn- 3 formant des micelles avec les sels biliaires, migrent vers la muqueuse intestinale et sont absorbés par les entérocytes pour la resynthèse de TAG qui passent ensuite dans la lymphe sous forme de chylomicrons (Trotter et Storch, 1993). Les AG à chaîne courte et moyenne qui sont libérés au cours de la digestion, sont directement absorbés par diffusion passive, transportés rapidement par l'albumine (via la veine porte) jusqu'au foie où ils sont métabolisés (Decker, 1996 ; Mu et Høy, 2001 ; Straarup et Høy, 2001 ; Osborn et Akoh, 2002).

Chez l'animal et le nouveau-né, les AG en position sn- 2 des TAG seraient plus rapidement absorbés sous forme de 2MAG que sous forme d'AG libres (Yang et Kuksis, 1991 ; Innis et al., 1994) mais ces observations ne sont pas clairement confirmées par les études cliniques chez l'adulte (Zampelas et al., 1994 ; Summers et al., 1999 ; Kindel et al., 2010).

Par la suite, la synthèse et la sécrétion des chylomicrons sont directement liées à la quantité de lipides absorbés (Norum et al., 1983). Les AG en position sn-2 dans les TAG alimentaires sont absorbés et restitués majoritairement à cette position dans les TAG des chylomicrons chez l'Homme. Généralement, un taux de $85 \%$ de conservation à cette position est décrit pour les AG saturés (Summers et al., 1999) mais dans des cas particuliers de TAG structurés, ce taux peut descendre à $66 \%$ (Tuomasjukka et al., 2009), ce qui implique une isomérisation (migration de l'acide gras de la position interne à la position externe dans le 2-MAG). Pour ce qui est des AG insaturés des huiles alimentaires, Boulos et Combe (2000) ont montré que lorsque I'acide $\alpha$-linolénique est réparti de façon homogène sur le TAG (i.e. $30 \%$ en position sn-2), sa distribution est conservée, tandis qu'il y a isomérisation quand I'AG est majoritairement en sn-2 comme dans I'huile de colza (50-60\% en position sn- 2 dans les TAG ingérés contre 40 à $44 \%$ dans les TAG lymphatiques). Selon Christensen et al. (1995), cette isomérisation serait due à l'activité d'enzymes intestinales qui hydrolyseraient les 2-MAG.

Les TAG circulants contenus dans les chylomicrons et les VLDL (very low density lipoproteins) sont ensuite hydrolysés par la lipoprotéine lipase (LPL), 
- Système complexe de particules en suspension dans un fluide aqueux (pH 6,0-6,5)

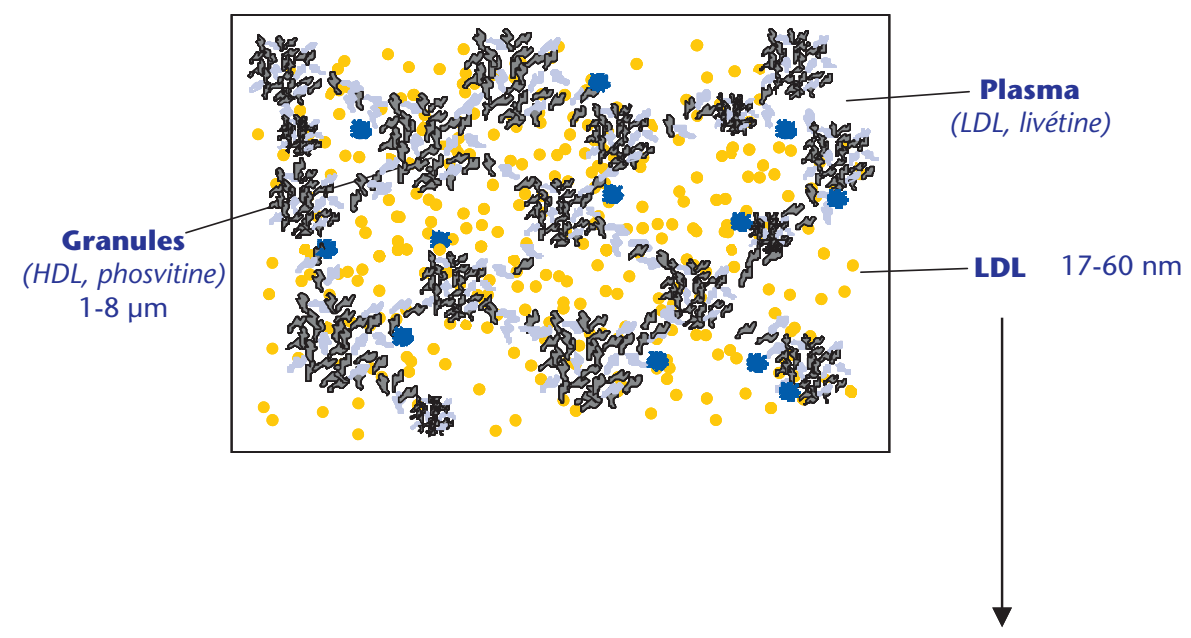

Nanostructure des LDL
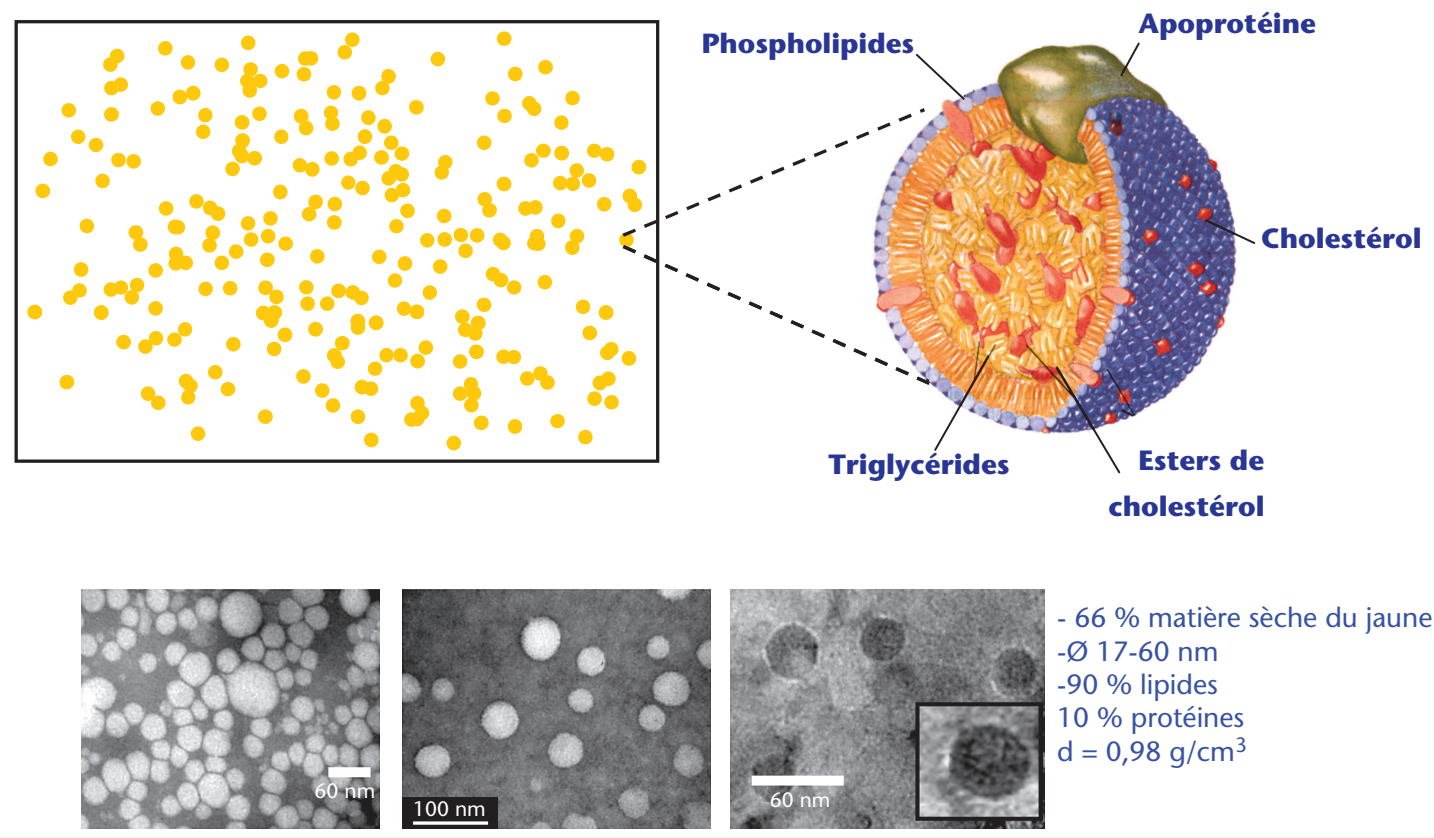

- $66 \%$ matière sèche du jaune

$-\varnothing 17-60 \mathrm{~nm}$

$-90 \%$ lipides

$10 \%$ protéines

$\mathrm{d}=0,98 \mathrm{~g} / \mathrm{cm}^{3}$

Figure 4. Composition et organisation des lipides de l'œuf : nanostructure des LDL (Anton M., Inra BIA, Nantes)

ancrée dans I'endothélium vasculaire (Scanu, 1966) pour libérer des AG qui sont métabolisés par les cellules.

\section{Cas des TAG naturels différemment structurés}

Chez le rat, l'absorption intestinale de graisses et huiles de différentes origines a été étudiée en quantifiant les AG dans la lymphe en cinétique postprandiale, $c^{\prime}$ est-à-dire dans les heures qui suivent
I'ingestion (Porsgaard et Hoy, 2000). Ces matières grasses présentaient des compositions en AG, des structures moléculaires et supramoléculaires ainsi que des propriétés de cristallisation différentes. D'après ces travaux, les pourcentages d'absorption des acides gras, 8 heures et 24 heures après l'ingestion de matières grasses dont les AG saturés sont majoritairement en position sn-1 et sn-3, à savoir du beurre de cacao (27 et $66 \%$ des AG totaux retrouvés dans la lymphe) et de I'huile de palme (36 et $67 \%$, respectivement), seraient plus faibles par rapport au saindoux (45 et $82 \%$ des AG totaux retrouvés dans la lymphe, respectivement) dans lequel les AG saturés sont en position sn-2.

Christensen et al. (1994) ont montré chez le rat également que le DHA et I'EPA 


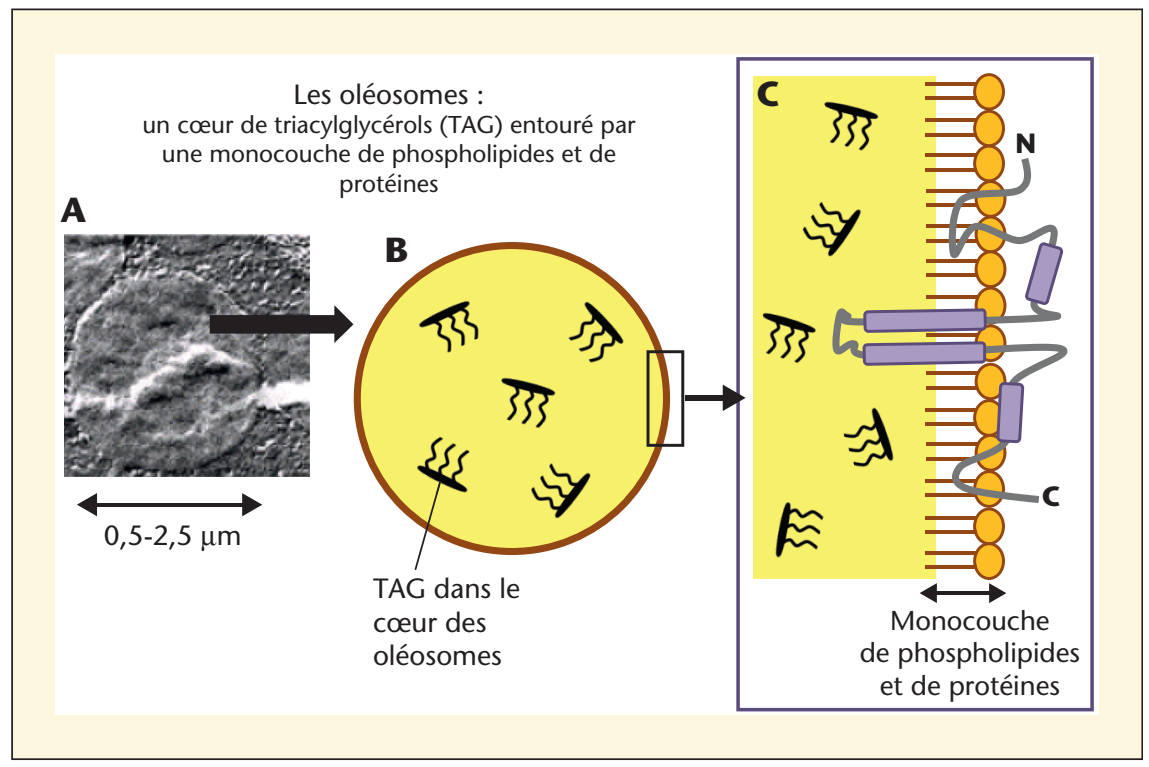

Figure 5. Organisation des lipides des graines oléagineuses: les oléosomes (illustration issue de Buchanan et al., 2000). A) Oléosome vu en microscopie électronique. B) Schéma d'un oléosome. C) Détail de la membrane d'un oléosome

de I'huile de poisson étaient mieux absorbés (quantification des AG dans la lymphe en cinétique postprandiale) au cours des premières heures que ceux de I'huile de phoque. Ce phénomène serait lié aux contraintes d'encombrement stérique pour l'accès des enzymes à leur substrat évoquées précédemment. Cependant, les effets ne sont plus statistiquement significatifs en considérant l'assimilation totale mesurée 24 heures après I'ingestion.

\section{Cas des TAG synthétiques et structurés par interestérification}

La position des chaînes d'AG sur les molécules de TAG peut être modifiée par un procédé appelé interestérification. Ce procédé qui utilise des méthodes catalytiques chimiques ou enzymatiques permet d'incorporer des AG spécifiques ou d'induire un réarrangement aléatoire ("randomization") des AG naturellement présents. Ce procédé offre une alternative à l'hydrogénation pour produire des margarines en modifiant le point de fusion des huiles végétales. L'industrie alimentaire utilise également ce procédé pour la conception d'aliments fonctionnels comme le Betapol ${ }^{\mathrm{TM}}$ utilisé dans certaines formulations infantiles pour mimer les TAG du lait maternel qui ont une forte proportion de $\mathrm{C} 16: 0$ en position sn-2 (De Fouw et al., 1994 ; Lucas et al., 1997).
Ce procédé appliqué à des lipides naturels et/ou des composés "purs" permet d'obtenir des TAG avec des structures aux caractéristiques particulières mais qui ne reflètent pas la complexité des structures observées dans les huiles naturelles. II permet également d'étudier l'impact du positionnement des AG sur leur absorption.

\section{Études chez l'animal}

Des études réalisées avec les TAG structurés par interestérification ont permis de montrer que la position des AG sur le glycérol pouvait modifier leur absorption, ce qui permettrait de moduler leur effet pro-athérogène potentiel.

Des études menées chez le rat sur des périodes longues (un mois) ont montré que la libération des AG par les lipases pancréatiques et que le taux de TAG plasmatiques étaient plus importants pour les TAG comportant un AG insaturé (C18:1 n-9, C18:2 n-6) en position centrale sn- 2 et des AG saturés (C8:0, $\mathrm{C} 10: 0$ ou $\mathrm{C} 16: 0)$ en positions externes sn-1 et sn-3 plutôt que l'inverse (Nagata et al., 2003, Jandacek et al., 1987 ; Carvajal et al., 2000). Par contre, une bonne absorption du C18:1 n-9, quelle que soit sa position sur des TAG uniquement constitués de $C 18: 0$ et $C 18: 1$ n-9, a été observée par Mattson et al. (1979). En ce qui concerne l'EPA et le DHA, les quantités transportées via la lymphe durant les 8 premières heures après l'ingestion étaient plus importantes (environ $18 \mathrm{mg}$ de chaque AG) lorsque ces AG étaient essentiellement en position sn-2 par rapport à une répartition plus homogène sur les 3 positions dans I'huile " randomisée " (environ $9 \mathrm{mg}$ de chaque AG) (Christensen et al., 1995). Néanmoins, cette étude ainsi que celles de Straarup et Høy (2001) et Porsgaard et al. (2005) ne montrent plus de différence significative concernant les quantités totales transportées par la lymphe après 24 heures. Un autre exemple est celui de l'acide ruménique (C18:2 $c 9, t 11)$ qui est un isomère conjugué de l'acide linoléique (CLA) issu de la biohydrogénation dans le rumen des animaux et présent dans les produits laitiers. Chez le rat, après administration de TAG contenant du CLA marqué au ${ }^{14} \mathrm{C}$, il ressort que ce dernier est mieux absorbé et oxydé (production d'énergie) après 16 heures lorsqu'il est en position externe des TAG $\left(48 \%\right.$ du ${ }^{14} \mathrm{C}$ est retrouvé dans le $\mathrm{CO}_{2}$ expiré), comme $c^{\prime}$ est le cas dans la matière grasse laitière, par rapport à une position en sn-2 sur un TAG synthétique $\left(28 \%\right.$ du ${ }^{14} \mathrm{C}$ seulement retrouvé dans le $\mathrm{CO}_{2}$ expiré) (Chardigny et al., 2003).

Toujours chez le rat, après 24 jours de régimes alimentaires enrichis en huiles de poisson ou de noisette randomisées ou natives, la structuration des TAG ne modifie pas l'absorption apparente des lipides évaluée par dosage des lipides dans les selles, le taux de cholestérol et de TAG plasmatiques et la composition en $A G$ des lipides plasmatiques à jeun (De Schrijver et al., 1991a, 1991b). Néanmoins, une meilleure absorption (2 à 3 fois moins d'excrétion fécale) du C16:0 (mais aussi du C14:0 et C18:0) a été observée après augmentation de sa proportion en position sn-2 par interestérification de TAG d'huile de noix de coco et de palme (Lien et al., 1993). Des résultats similaires ont été obtenus chez le porcelet lorsque le C16:0 est majoritairement estérifié en position sn-2 des TAG en comparant de I'huile de palme et du saindoux, natifs ou interestérifiés (Renaud et al., 1995) ou des formulations laitières (Innis et al., 1995, 1997).

Chez le lapin, l'interestérification de différentes huiles et graisses ne modifie pas les taux plasmatiques de lipides et de lipoprotéines. Par contre, plus la 


\section{A Structure supramoléculaire et digestion : état émulsionné}

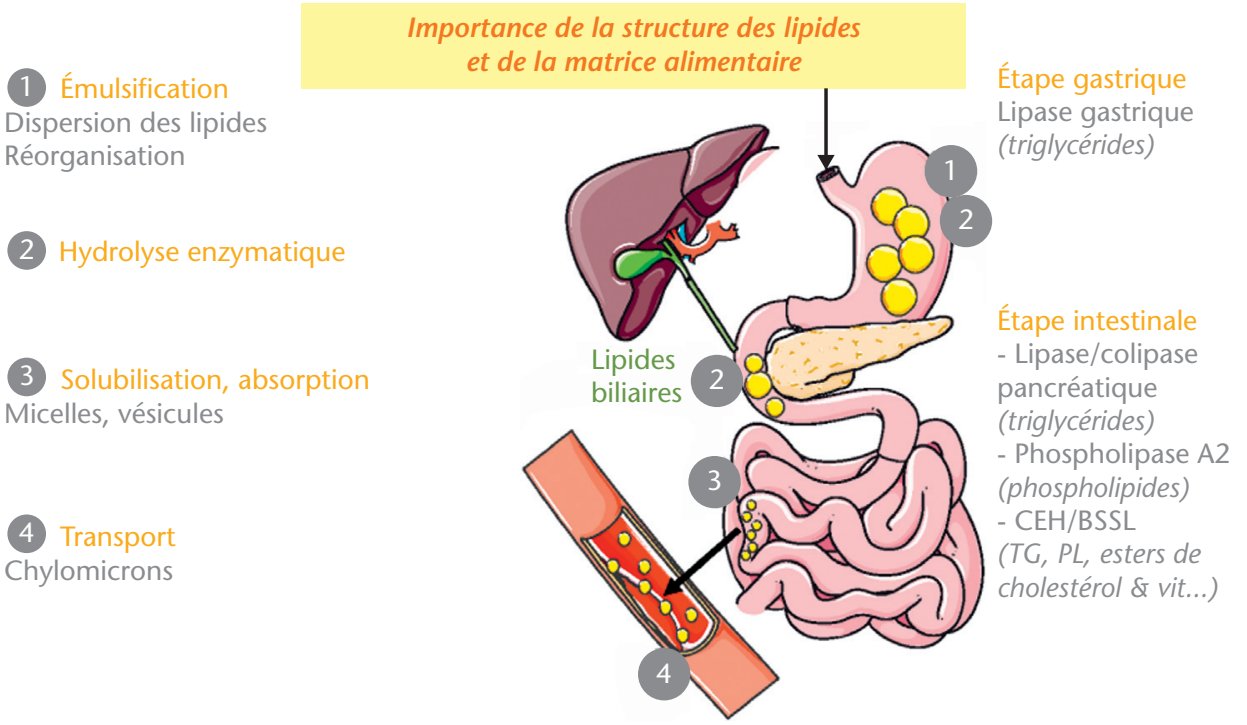

\section{B Structure moléculaire et digestion : triglycérides}

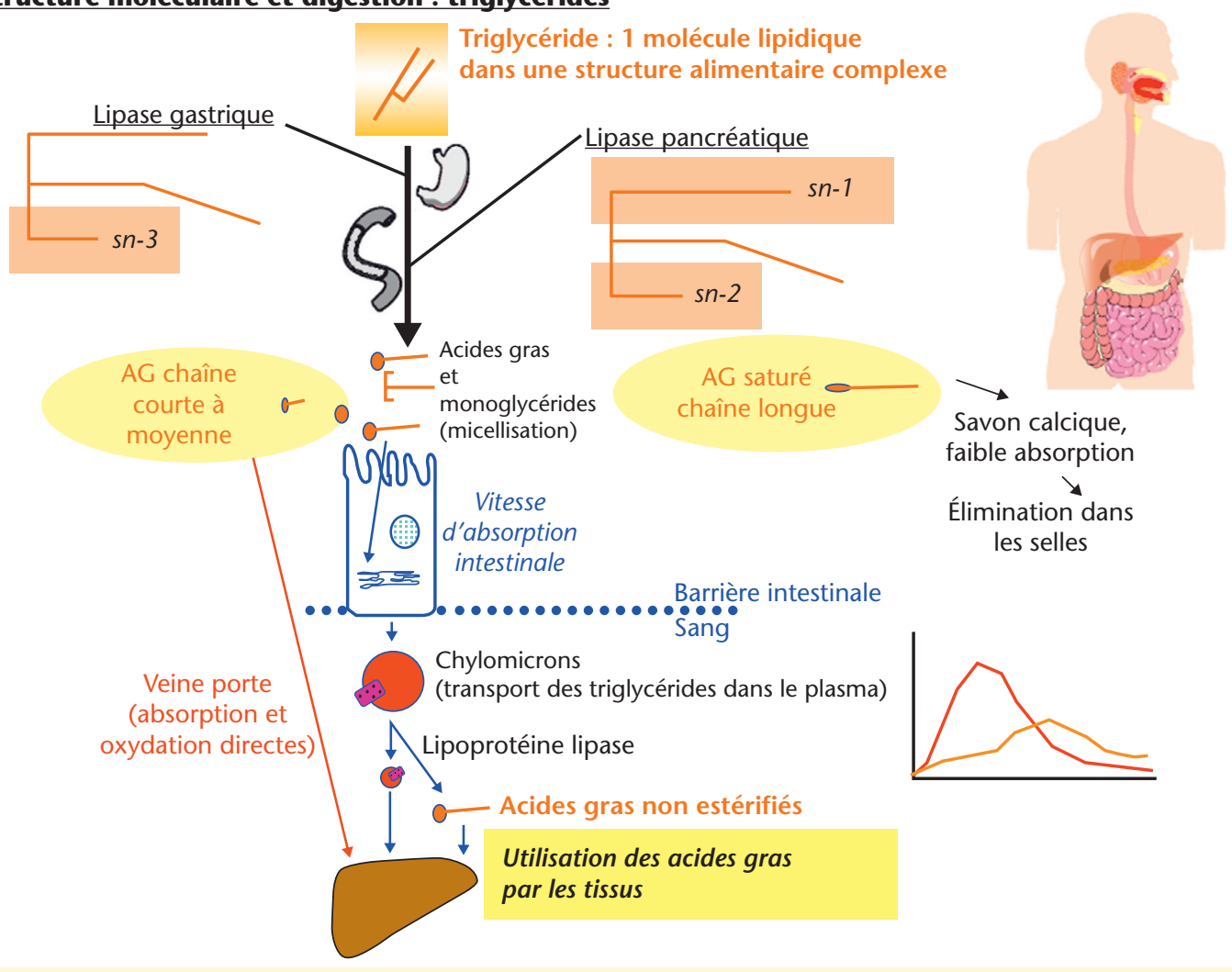

Figure 6. Importance des structures dans la digestion et l'absorption des lipides. Adapté de Armand (2007), Michalski (2009) et Genot et Michalski (2010). Illustration réalisée grâce à Servier Medical Art. 
proportion de C16:0 estérifié en position sn-2 est élevée par rapport aux positions externes, plus l'effet athérogène, évalué par l'appréciation visuelle des dépôts dans I'aorte après 60 jours, est important (Kritchevsky et al., 1998a, 1998b). En effet, selon cette évaluation, le saindoux est plus athérogène à l'état natif, dans lequel le C16:0 est principalement en position sn-2, que lorsqu'il est interestérifié (Kritchevsky et al., 1998a) tandis que les huiles de palme et de graines de coton natives, dont le $\mathrm{C} 16: 0$ est principalement en sn- 1 et sn-3, sont moins athérogènes que les mêmes huiles interestérifiées (Kritchevsky et al., 1998b, 2000a). Les auteurs suggèrent que ces effets seraient dus à une meilleure absorption et une rémanence du C16:0 dans la circulation lorsque celui-ci est estérifié en position sn-2 comme cela a été montré par Redgrave et al. (1988) et Mortimer et al. (1994).

\section{Études chez I'Homme}

Chez le nouveau-né, l'absorption du C16:0 est meilleure lorsque celui-ci est en position sn- 2 sur les TAG : 8 fois moins de pertes fécales avec du saindoux natif où le $\mathrm{C} 16: 0$ est en position sn-2 vs. du saindoux randomisé selon Filer et al. (1969). Dans le lait maternel, le C16:0 majoritairement estérifié en position sn-2 semble alors mieux absorbé par le nouveau-né que le lait de vache et certaines formulations infantiles où il est essentiellement réparti sur les positions sn-1 et sn-2 (Innis et al., 1994; Lien, 1994 ; Straarup et al., 2006). En revanche, les résultats observés chez l'adulte sont parfois contradictoires et ne permettent pas de conclure sur des différences d'absorption selon la position de l'acide palmitique en sn-1 et/ou sn-2 (Hunter, 2001 ; Kubow, 1996 ; Zampelas et al., 1994 ; Summers et al., 1999 ; Kindel et al., 2010).

Des mesures réalisées en phase postprandiale mettent en évidence des taux de TAG identiques dans le plasma comme dans les différentes fractions de lipoprotéines six heures après consommation de matières grasses riches en C16:0 ou C18:0 et de structures intramoléculaires différentes (Zampelas et al., 1994). Selon Summers et al. (1998, 1999), lorsque la position en sn-2 des TAG est conservée en grande partie (85\%) au niveau de l'entérocyte, il se produirait au niveau des tissus (adipeux par exemple) une isomérisation des 2MAG des chylomicrons (portant un C18:0) en 1(3)-MAG qui seraient ainsi hydrolysés par la lipoprotéine lipase (LPL). En effet, il est démontré chez I'animal que cette lipase est spécifique des positions sn- 1 et sn- 3 des TAG. Ceci expliquerait l'absence d'effet de la structuration des TAG pour ces AG saturés. Tuomasjukka et al. (2009) ont montré des taux d'isomérisation plus importants au niveau de l'entérocyte $(66 \%$ de conservation du C18:0 en sn-2) en utilisant un TAG structuré $(30 \%$ de C18:0 en sn-2).

En revanche, pour d'autres auteurs (Yli-Jokipii et al., 2001, 2003 ; Berry et al., 2007b), la lipémie exprimée en tant qu'aire sous la courbe des TAG plasmatiques semble plus faible lorsque le $\mathrm{C} 16: 0$ est majoritairement en sn-2, comme dans du saindoux natif ou réparti uniformément sur les trois positions pour de I'huile de palme interestérifiée, que lorsque le C16:0 est réparti de façon homogène pour le saindoux interestérifié, ou majoritairement positionné en positions sn- 1 et sn- 3 dans le cas de I'huile de palme native. Dans ces conditions, la composition en AG des TAG dans les chylomicrons ne subit pas de modifications importantes par rapport aux TAG ingérés.

D'après ces observations, il semble que la cinétique d'absorption des lipides chez l'adulte soit davantage corrélée au pourcentage de lipides solides à température corporelle qu'à la position des AG saturés sur le glycérol. En effet, lors du réarrangement des $A G$ sur la molécule de TAG, les propriétés thermiques des lipides sont modifiées. L'augmentation du point de fusion des TAG tri-saturés induit une diminution de la lipémie postprandiale comme cela est décrit dans le chapitre suivant. Des études complémentaires seront nécessaires pour distinguer l'impact des propriétés thermiques et de la proportion d'AG saturés à longue chaîne en position sn-2.

Enfin, des essais cliniques réalisés chez des sujets sains ou hypercholestérolémiques pendant 3 à 4 semaines, ont montré que la consommation de graisses interestérifiées n'avait pas d'impact sur les taux de lipides sanguins (LDL-cholestérol, HDL-cholestérol et triglycérides à jeun) par rapport à la consommation de graisses natives que ce soient des mélanges d'huiles végétales (Meijer et Weststrate, 1997), du beurre de karité (Berry et al., 2007a), du beurre (Christophe et al., 2000) ou de l'huile de palme (Zock et al., 1995, Nestel et al., 1995).

\section{Phospholipides vs. triacylglycérols}

Dans les premières phases de la digestion, la fonction ester en position sn-2 des phospholipides est hydrolysée par la phospholipase A2 pancréatique qui libère ainsi un lyso-phospholipide et un AG (Hanahan, 1997 ; Wilton, 2008). L'hydrolyse pourrait être complétée par l'action de la protéine apparentée à la lipase pancréatique de type 2 (PLRP2), en position sn-1 (Whitcomb et Lowe, 2007 cité par Armand, 2008). Les études visant à comparer le devenir métabolique des AG, AGPI essentiellement, selon qu'ils sont portés par des PL ou des TAG, donnent souvent avantage aux PL. Néanmoins, du fait de leur caractère polaire, leur agencement (ex : liposomes) diffère par rapport à celui des TAG et doit également être pris en compte dans les interprétations.

L'effet hypotriglycéridémiant des oméga3 à longue chaîne (EPA et DHA) d'origine marine est similaire lorsqu'ils sont apportés sous forme de PL ou de TAG pendant 2 semaines chez le rat (Cansell et al., 2006). En revanche, leur incorporation dans les lipides plasmatiques et le foie est meilleure lorsqu'ils sont apportés par des PL agencés sous forme de liposomes par rapport à des TAG apportés sous forme d'huile (Cansell et al., 2003, 2006). Plus récemment, les mêmes auteurs (Cansell et al., 2009), en étudiant le métabolisme hépatique, ont observé une $\beta$-oxydation précoce de I'EPA lorsqu'il est apporté sous forme de $\mathrm{PL}$ (structurés en liposomes).

Chez le rat, l'excrétion fécale de lipides au bout de 3 semaines de régime est légèrement moins importante lorsque I'apport d'AGPI est réalisé sous forme de PL d'œuf que sous forme de TAG d'œuf et I'inverse est observé entre PL de cervelet de porc et TAG d'huiles marines (Amate et al., 2002). Par ailleurs, ces auteurs ont montré chez le porcelet que les concentrations en acide arachidonique (AA; C20:4 n-6) et en DHA étaient plus importantes dans les HDL quand les AGPI étaient ingérés sous forme de PL que sous forme de TAG, ce qui traduit un meilleur acheminement vers les tissus. En 
revanche, les taux de TAG et de cholestérol plasmatiques étaient similaires entre les deux régimes (Amate et al., 2001). À l'inverse, Mathews et al. (2002) ont observé chez le porcelet que l'apport pendant 16 jours de DHA sous forme de TAG (huile d'algues unicellulaires) induisait une concentration plasmatique totale en DHA plus importante qu'un apport sous forme de PL d'œuf, malgré des compositions en $\mathrm{AG}$ très similaires. Enfin, chez le nouveau-né, des résultats contradictoires ont été obtenus en comparant la biodisponibilité du DHA entre des formulations enrichies en PLDHA ou en TAG-DHA avec, soit un avantage pour les PL (Carnielli et al., 1998), soit des résultats similaires pour les deux formes d'apport en DHA (SalaVila et al., 2004). Chezl'Homme, certains essais cliniques visant à comparer les effets de l'EPA et du DHA selon qu'ils sont apportés par de l'huile de krill ou de I'huile de poisson concluent à un bénéfice plus important pour l'huile de krill, très riche en PL (40 à $60 \%$ des lipides) (Bunea et al., 2004 ; Kidd, 2007 ; Tou et al., 2007).

De fait, il apparaît dans ces études, qu'il est souvent difficile de différencier les effets de la molécule vectrice (PL ou TAG), la position de l'AG sur la molécule vectrice, la structure supramoléculaire (ex : liposome) ou l'état de dispersion de la matière grasse. De même, il est difficile de conclure aux bénéfices nutritionnels propres des lipides polaires intégrés dans les membranes de globules gras du lait pour lesquels des revues ont été publiées (Spitsberg, 2005; Ward et al., 2006 ; Lopez, 2011). Des applications en nutraceutique ont été évoquées (Corredig et al., 2003 ; Dewettinck et al., 2008 ; Thompson et Singh, 2006 ; Ward et al., 2006 ; Wat et al., 2009 ; Lund et Tholstrup, 2004).

Contrairement aux résultats des études appréciant les évolutions de lipides plasmatiques, les études d'incorporation de ces AG aux organes cibles chez l'animal confirment avec certitude l'efficacité des PL comme transporteurs comme cela a été démontré sur le cerveau de souris avec l'acide linoléique (Werner et al., 2004), le DHA dans les érythrocytes du rat (Valenzuela et al., 2005) et I'AA dans le cerveau chez le babouin (Wijendran et al., 2002). Dans un modèle d'hypoxie expérimentale chez le rat, la supplémentation avec du DHA sous forme PL d'œuf a permis, contrairement à un apport sous forme de TAG d'algues, une conservation partielle des capacités respiratoires visualisées à la fois en termes d'endurance à l'effort et en termes d'activité des paramètres de la chaîne respiratoire (Tardieu et al., 2009 d'après Pieroni et Coste, 2010).

Chez I'Homme, la consommation de jaune d'œuf enrichi en PL-DHA permet d'augmenter la proportion de DHA dans les lipides plasmatiques et les membranes d'érythrocytes des personnes âgées (Payet et al., 2004). L'utilisation de lécithines riches en lyso-phosphatidylcholine s'avère particulièrement intéressante pour améliorer le transport et la captation des AGPI tels que le DHA par le cerveau (Lagarde et al., 2001 ; Thies et al., 1992 ; Lagarde et al., 2009).

Enfin, d'un point de vue nutritionnel mais également sensoriel et techno-fonctionnel, le DHA pourrait être moins susceptible à l'oxydation lorsqu'il est sous forme de $\mathrm{PL}$, en comparaison à des TAG ou EE (Song et Miyazawa, 1997). Cependant, si les effets antioxydants de PL comme la phosphatidyl-éthanolamine en synergie avec les tocophérols semblent bien démontrés (Judde et al., 2003 ; Takenaka et al., 2007), les études comparant la susceptibilité à l'oxydation des AG selon qu'ils sont portés par un TAG, structuré ou non (Wang et Shahidi, 2011), ou par un $\mathrm{PL}$ restent souvent difficiles à interpréter en raison de l'interférence de plusieurs facteurs (organisation des lipides dans le système étudié, concentrations en antioxydants non ajustées par exemple) (Martin et al., 2010).

\section{Autres lipides structurés à applications alimentaires}

Outre les TAG et PL, des esters éthyliques sont utilisés comme molécules vectrices d'AG oméga-3 à longue chaîne (EPA et DHA) que l'on peut trouver dans des compléments alimentaires (capsules par exemple). La transformation des lipides en esters éthyliques a pour objectif d'augmenter spécifiquement la concentration d'un ou de quelques AG ciblés. $C^{\prime}$ est par exemple la voie technologique qui permet d'avoir des mélanges de lipides ayant plus de $70 \%$ de DHA. Certains travaux montrent que I'incorporation d'AG oméga-3 à longue chaîne dans les lipides plasmatiques est plus efficace quand ils sont administrés sous la forme d'esters éthyliques par rapport aux formes TAG et PL chez le rat (Hamazaki et al., 1987). Cette forme serait cependant moins efficace chez l'Homme après une seule prise (Lawson et Hughes, 1988) mais les résultats obtenus après 14 jours (28 g d'ester par prise) chez I'Homme ne montrent pas de différences entre les trois formes d'apport (Krokan et al., 1993 ; Nordoy et al., 1991). En effet, ce serait davantage la cinétique d'absorption de I'EPA et du DHA qui est influencée par la forme d'apport que la quantité totale d'AG retrouvée dans la circulation après plusieurs heures (Ikeda et al., 1993, 1995).

Parmi les lipides neutres, outre les TAG, les 1-3 diacylglycerols (1-3 DAG) sont également étudiés. De nouvelles huiles riches en 1-3 DAG, obtenues à partir $d$ 'huiles végétales ordinaires par un procédé d'hydrolyse, souvent riches en acides oléique et linoléique, sont reconnues comme GRAS ("Generally Recognized As Safe") et peuvent donc être utilisées dans I'alimentation (Takase, 2007). Les études chez l'animal et chez I'homme suggèrent des effets positifs sur le métabolisme lipidique (Hara et al., 1993 ; Maki et al., 2009 ; Saito et al., 2006 ; Taguchi et al., 2000 ; Rudkowska et al., 2005; Tamai et al., 2007; Yamamoto et al., 2006).

Le groupe Nabisco Foods a développé dans les années 90 un substitut lipidique faiblement calorique appelé Salatrim ${ }^{\circledR}$ et utilisé comme ingrédient (Dir 2003/120/ CE). Il s'agit en réalité de TAG formés par interestérification $d$ 'huiles végétales hydrogénées riches en C18:0 et de TAG à très courtes chaînes (triacétine, tripropionine et tributyrine). Ces TAG contiennent deux $A G$ à chaîne courte et un C18:0 estérifié aléatoirement sur les 3 positions du glycérol, donc majoritairement $(67 \%)$ en position externe (Softly et al., 1994). Ce dernier est donc faiblement absorbé pour les raisons décrites plus haut et les AG courts absorbés sont très peu caloriques (Livesey, 2000). Finley et al. (1994a, 1994b) ont montré chez le rat et chez l'Homme que les salatrims étaient moins caloriques que les huiles végétales utilisées traditionnellement dans l'industrie agroalimentaire. Sanders et al. (2001) ont montré chez I'Homme que la consommation de Salatrim ${ }^{\circledR}$ 23SO (fabriqué à partir de triacétine, tripropionine et huile de soja) induit une lipémie postprandiale deux fois moins importante, dans les 6 heures après ingestion, que la consommation d'un régime contenant de l'huile de 
tournesol ou d'un régime contenant du beurre de cacao.

Le groupe Procter \& Gamble commercialise également un substitut lipidique appelé Olestra $^{\circledR}$ (saccharose estérifié avec 6 à 8 acides gras d'origine végétale) sous la marque Olean ${ }^{\circledR}$, autorisé uniquement aux États-Unis. Ce substitut a été approuvé par la FDA pour être utilisé dans la préparation de chips, snacks et cookies. Non hydrolysé par les lipases gastriques et pancréatiques, Olestra ${ }^{\circledR}$ n'est pas absorbé au niveau de l'intestin grêle et est excrété dans les selles (Jandacek et al., 1999 ; Lawson et al., 1997) mais avec des effets indésirables possibles (diarrhées).

\section{Influence de I'organisation de la matière grasse dans I'aliment}

\section{Influence de l'état physique de la matière grasse}

\section{Généralités}

Les huiles et graisses naturelles alimentaires sont des mélanges d'un grand nombre d'espèces de TAG. La longueur de chaîne des AG, leur degré d'insaturation ainsi que la position des AG sur les 3 positions du glycérol dirigent les propriétés physiques des matières grasses, particulièrement leurs propriétés de cristallisation et de fusion. Le tableau 4 reprend les points de fusion de différents TAG purs en fonction de leur forme cristalline d'après Mortensen (2009).

Les matières grasses riches en AG saturés à longue chaîne ont un point de fusion élevé ; par exemple, le saindoux et le suif ont une forte proportion de TAG qui

Tableau 4. Points de fusion $\left({ }^{\circ} \mathrm{C}\right)$ de différents triglycérides purs en fonction de leur forme cristalline (d'après Mortensen, 2009).

\begin{tabular}{|llll|}
\hline & Formes cristallines & & \\
\hline & $\begin{array}{l}\text { Hexagonale } \\
(\alpha)\end{array}$ & $\begin{array}{l}\text { Orthorhombique } \\
\left(\beta^{\prime}\right)\end{array}$ & $\begin{array}{l}\text { Triclinique } \\
(\beta)\end{array}$ \\
\hline Tricapryline & -51 & -18 & +10 \\
\hline Tricaprine & $+10,5$ & +17 & +32 \\
\hline Trilaurine & +15 & +34 & +46 \\
\hline Trimyristine & +33 & +46 & +58 \\
\hline Tripalmitine & +45 & +56 & +66 \\
\hline Tristéarine & +55 & +64 & +73 \\
\hline Trioléine & -32 & -12 & +5 \\
\hline
\end{tabular}

formes polymorphiques principales : $\alpha, \beta^{\prime}$ et $\beta$ dans leur ordre croissant de compacité des chaînes d'AG et de stabilité (figure 7B). Il existe d'autres sous-variétés cristallines et les mélanges complexes de TAG sont souvent caractérisés par la coexistence de 6 à 7 variétés cristallines différentes (Himawan et al., 2006 ; Ollivon et Perron, 1992 ; Sato et al., 1999 ; Walstra, 2003). La présence de ces différentes formes polymorphiques dépend donc de la nature des TAG présents et de leur miscibilité mais aussi de la température, de la cinétique de refroidissement, de la pression ou de la vitesse de cisaillement. Ces paramètres influencent également la taille des cristaux. En effet, une cristallisation lente favorise l'apparition de cristaux de grande taille (Cansell, 2005). quantité de TAG à l'état solide dépend principalement de la composition en TAG et de la température.

Le polymorphisme des TAG correspond à l'aptitude des molécules à s'organiser latéralement (figure $7 B$ ) et longitudinalement (figures $7 A$ et $C$ ) au sein $d^{\prime} u n$ cristal selon différentes conformations. Récemment, le développement de nouveaux outils couplant la microcalorimétrie différentielle (DSC) et la diffraction des rayons $X$ (DRX) résolue en temps ont permis de caractériser finement les propriétés de cristallisation et le polymorphisme des TAG dans différentes matrices alimentaires (Lopez et al., 2007a ; Ollivon et al., 2006). Une technique de RMN (résonance magnétique nucléaire) a également été proposée pour étudier le polymorphisme des TAG (Adam-Berret et al., 2008). Dans les cristaux, les TAG sont généralement organisés en structures lamellaires à 2 ou 3 longueurs de chaînes d'AG (2L, 3L) (figures $7 A$ et $C$ ) avec coexistence de 3

L'état de dispersion des TAG influe sur la température de début de cristallisation, les propriétés polymorphiques des TAG ainsi que sur le comportement microscopique des cristaux (taille, forme, orientation, position au sein de la gouttelette) (Cansell, 2005 ; Coupland, 2002 ; Lopez et al., 2002). Par rapport à la matière grasse en milieu continu, les mécanismes de nucléation dus aux impuretés sont différents lorsque les TAG sont dispersés dans des gouttelettes d'émulsion. Les tensioactifs peuvent servir de point de nucléation pour la cristallisation des TAG et jouer un rôle important dans leur cristallisation en émulsion (Awad et Sato, 2002 ; Lopez et Ollivon, 2009a; Palanuwech et Coupland, 2003). Par exemple, la présence de lipides polaires dans une matrice continue de matière grasse ou une émulsion peut modifier la cristallisation des TAG (Garbolino et al., 2005 ; Toro-Vazquez et al., 2005). La température de cristallisation de la matière grasse en émulsion est inférieure à celle des systèmes continus et donc la proportion de lipides solides à une température donnée est plus faible (Campbell et al., 2002 ; Cansell, 2005). La taille des gouttelettes d'émulsion influerait également sur les propriétés de cristallisation des TAG (Campbell et al., 2002 ; Lopez et al., 2002). En revanche, l'impact de l'émulsification sur le polymorphisme des TAG au cours de la cristallisation semble dépendre majoritairement de l'origine de la matière grasse (Lopez et al., 2000, 2005 ; Campbell et al., 2002 ; Kalnin et al., 2002 ; Lopez et Ollivon, 2009a). 


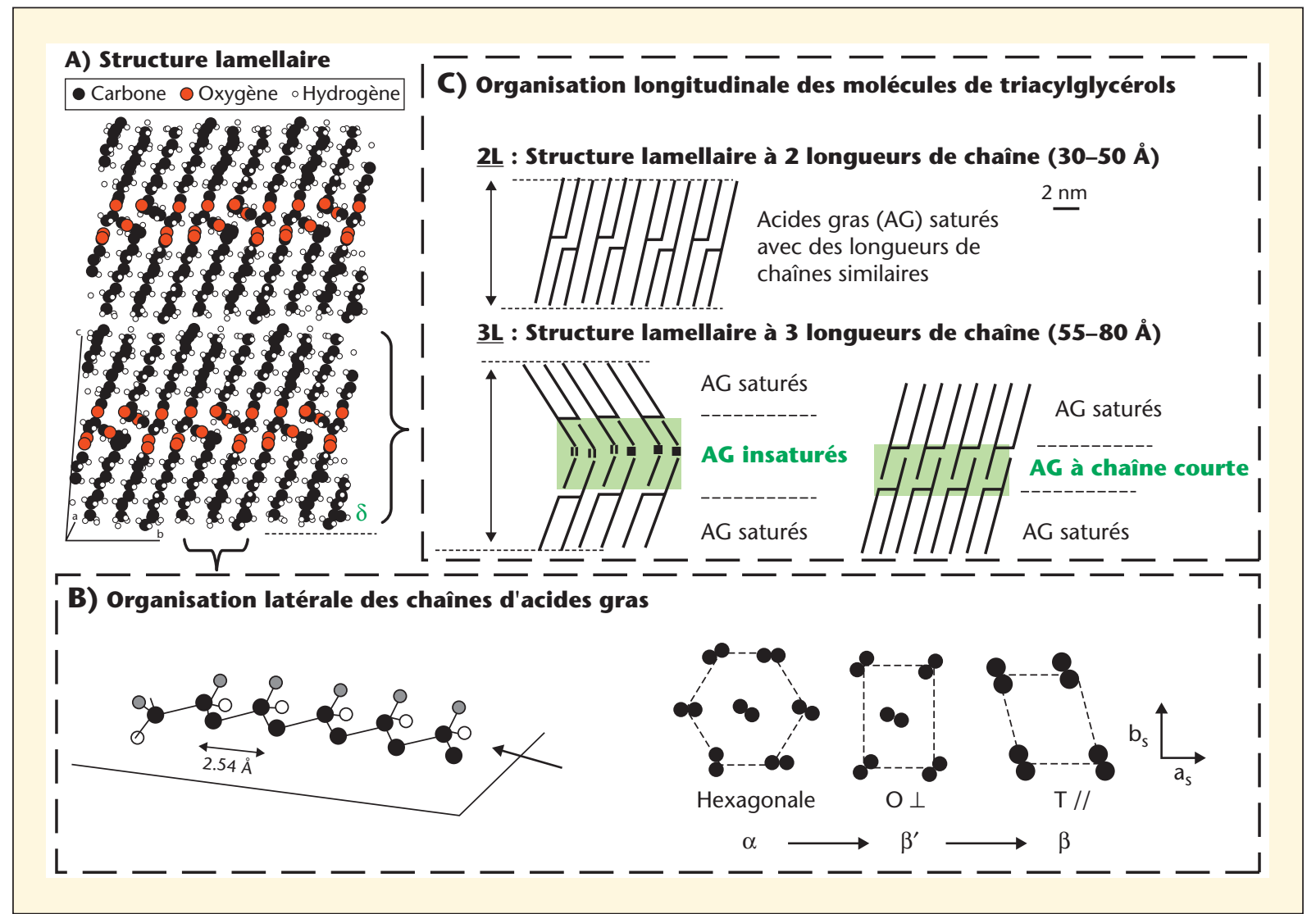

Figure 7. Différentes formes cristallines: organisation longitudinale des molécules de triacylglycérols (TAG) et organisation transversale des chaînes d'acides gras (adapté de Lopez et al., 2007a).

Enfin, il a été largement montré que la cristallisation des TAG modifie la stabilité de l'émulsion (Rousseau, 2000) et la maîtrise des process associés constitue un challenge important notamment dans le domaine pharmaceutique pour la conception de systèmes de vectorisation de molécules hydrophobes (Muchow et al., 2008).

\section{Propriétes thermiques \\ et polymorphisme d'huiles \\ et graisses naturelles}

Les propriétés de cristallisation de l'huile de palme et de ses dérivés ont été largement étudiées. À température ambiante, I'huile de palme est semisolide et plusieurs des structures cristallines décrites ci-dessus ont été observées (Braipson-Danthine et Gibon, 2007 ; Che Man et al., 1999).

Le polymorphisme du beurre de cacao est généralement décrit par 6 formes polymorphiques notées de I à VI dans l'ordre croissant des points de fusion. L'état de cristallisation du beurre de cacao joue un rôle très important dans les propriétés de texture, de brillance et de cassant du chocolat (Afoakwa et al., 2009 ; Loisel et al., 1998).

Les propriétés de cristallisation et de fusion de la matière grasse laitière ont été étudiées en milieu anhydre, en émulsion et dans des matrices complexes. Lopez et al. (2007a) ont mis en évidence 6 structures cristallines différentes dans les globules gras du lait, plusieurs pouvant coexister au sein d'une phase liquide. La taille des globules gras affecte les mécanismes de cristallisation et la taille des cristaux (Lopez et al., 2002; Michalski et al., 2004). La modification de l'état de dispersion des lipides, déstabilisation des globules par agrégation ou coalescence et formation de matière grasse libre pendant la fabrication des fromages comme l'emmental, altère les propriétés thermiques de la matière grasse (Lopez et al., 2006, 2008 ; Lopez et Briard-Bion, 2007 ; Lopez et Gaucheron, 2008). Lopez et al. (2006 et 2008) ont montré que la phase grasse est partiellement cristallisée dans les matrices fromagères pour une température inférieure à $41{ }^{\circ} \mathrm{C}$ et qu'environ $3 \%$ de la matière grasse est solide à $37^{\circ} \mathrm{C}$ et plus de $50 \%$ à $4{ }^{\circ} \mathrm{C}$.

La cristallisation des graisses animales autres que la matière grasse laitière est moins documentée. Kalnin et al. (2005) ont observé 4 formes polymorphiques dans le saindoux $\left(\alpha, \beta, \beta^{\prime}{ }_{1}\right.$ et $\left.\beta^{\prime}{ }_{2}\right)$ avec une plage de fusion allant de $-30{ }^{\circ} \mathrm{C}$ à $50^{\circ} \mathrm{C}$. Svenstrup et al. (2005) ont également observé des différences $d$ 'une part, entre de la matière grasse issue du tissu adipeux dorsal et de la matière grasse issue du gras périrénal, et d'autre part, entre du gras natif et de la matière grasse anhydre issue du gras de porcs.

II ressort de ces données une très grande importance de la structure cristalline des TAG d'un corps gras sur ses propriétés de cristallisation et de fusion.

\section{Impact sur la digestion, I'absorption} et le métabolisme des lipides

Les propriétés thermiques de la matière grasse et plus particulièrement la proportion de TAG solides à $37{ }^{\circ} \mathrm{C}$ pourraient modifier la digestion, I'absorption et le métabolisme des lipides alimentaires 
(Livesey, 2000). En effet, la présence de TAG sous forme solide limite leur hydrolyse par les enzymes digestives et donc leur absorption. Bonnaire et al. (2008) ont montré in vitro que les cinétiques et taux d'hydrolyse par les lipases pancréatiques d'une émulsion de tripalmitine (tri-C16:0) totalement solide, après 2 heures d'incubation, sont plus faibles (35\% d'hydrolyse des TAG) que pour une émulsion similaire dont les TAG sont sous forme liquide (55\% d'hydrolyse).

Crockett et Deuel (1947) ont montré que, chez le rat, la digestion et l'absorption de matières grasses naturelles et d'autres dont la structure a été modifiée sont corrélées avec leur température de fusion, avec une diminution importante au-delà de $50^{\circ} \mathrm{C}$. Bergstedt et al. (1990) ont montré chez le rat également que la tri-stéarine (tri-C18:0 ; température de fusion $=73{ }^{\circ} \mathrm{C}$ ) est moins bien digérée et absorbée que la trioléine (tri-C18:1 $\mathrm{n}$-9) entièrement liquide à $37^{\circ} \mathrm{C}$. De même, chez le cochon d'Inde (Asselin et al., 2004) ou le rat (Lai et Ney, 1998) nourris avec des fractions de matière grasse de lait à haut point de fusion (fraction stéarique), il a été montré que I'absorption des lipides (taux de TAG plasmatiques ou aire sous la courbe des TAG plasmatiques en cinétique postprandiale) est plus faible que chez des animaux nourris avec une fraction à bas point de fusion (fraction oléique). Les effets semblaient plus prononcés sur le cholestérol que sur les TAG plasmatiques (Lai et al., 1995). Ces fractions de la matière grasse du lait ont des compositions en AG différentes et en conséquence un pourcentage différent de TAG solides à une température donnée, un polymorphisme et un comportement thermique différents (Lopez et Ollivon, 2009b). Ainsi, les résultats observés peuvent s'expliquer par le fait que l'état physique des TAG modifie la faculté des lipases à s'adsorber à la surface des gouttelettes et que l'empilement en feuillets des molécules de TAG à l'état solide rende les chaînes acyles moins accessibles au site actif des enzymes. Toutefois, la fraction avec une température de fusion élevée est plus riche en C16:0 ce qui peut également avoir un impact sur l'absorption des lipides indépendamment de l'état physique de la matière grasse.

La température de fusion élevée (supérieure à $37^{\circ} \mathrm{C}$ ) des TAG riches en
C16:0 ou C18:0 serait responsable de la faible cinétique d'absorption de ces AG chez I'Homme (Berry et Sanders, 2005 ; Berry, 2009). Plusieurs études ont montré que les différents pourcentages de lipides solides à $37{ }^{\circ} \mathrm{C}$ entre des huiles ou de graisses natives et randomisées influent sur la lipémie postprandiale. Par exemple, Sanders et al. (2003) ont observé une quantité de TAG plasmatiques plus faible de $41 \%$ pour du beurre de cacao interestérifié par rapport à beurre de cacao natif (riche en POS et $\mathrm{SOS}^{2}$ ). Après interestérification, le beurre de cacao contient une plus grande proportion de TAG dont les 3 chaînes acyles sont saturées (PPP, PPS, SSP et SSS). Ces TAG ont des points de fusion élevés (63 à $73{ }^{\circ} \mathrm{C}$ ) et ainsi $37 \%$ des lipides sont à l'état solide à $37{ }^{\circ} \mathrm{C}$ dans le beurre interestérifié contre $1 \%$ dans le beurre de cacao natif. Ces auteurs observent une incorporation du C16:0, du C18:0 et du C18:1n-9 dans les lipides plasmatiques plus élevée pour le beurre de cacao natif. Les mêmes observations ont été réalisées pour des comparaisons entre huile de palme randomisée et huile de palme native (Berry et al., 2007b). Robinson et al. (2009) ont montré que les sujets obèses (risque de diabète ou de maladie cardiovasculaire) étaient davantage exposés (aire sous la courbe des TAG plasmatiques en cinétique postprandiale pendant 6 heures) que des sujets sains lorsqu'ils consommaient un mélange d'huiles de tournesol et de colza hydrogéné préalablement randomisé et présentant ainsi seulement $6 \%$ de lipides solides à $37^{\circ} \mathrm{C}$ (SOS et OOS comme principaux types de TAG) par rapport au même mélange natif contenant $19 \%$ de lipides solides à $37{ }^{\circ} \mathrm{C}$ (riche en $\mathrm{OOO}$ et SSS).

\section{Influence de l'état de dispersion de la matiere grasse}

Les lipides alimentaires (principalement TAG et $\mathrm{PL}$ ) peuvent être présents sous forme de matière grasse libre ou sous forme dispersée dans une phase liquide ou solide, on parle alors de systèmes colloïdaux. II existe plusieurs types de systèmes colloïdaux selon la nature des lipides et la présence ou non de protéines. La forme la plus classique est l'émulsion huile dans eau dont les agents stabilisants (surfactants) sont généralement des phospholipides et/ou des protéines. La dispersion de molécules amphiphiles comme les PL dans un milieu aqueux induit la formation de micelles ou de liposomes, selon la géométrie de la molécule. Toutefois, dans l'alimentation, les PL sont présents dans les membranes cellulaires (viande et chair de poisson) ou à l'interface des émulsions (membrane des globules gras du lait et des oléosomes) mais rarement sous forme de liposomes. Les produits riches en PL comme les lécithines d'origine végétale (soja, colza, tournesol) ou animale (jaune d'œuf, cervelle, krill) peuvent encore contenir jusqu'à $40 \%$ de lipides neutres ainsi que des protéines et se présentent donc sous forme liquide ou sous forme pâteuse. La lécithine de soja totalement déshuilée qui est utilisée dans l'industrie alimentaire comme émulsifiant est sous forme de poudre.

Contrairement à la plupart des enzymes qui agissent en phase aqueuse, les lipases agissent en milieu hétérogène, à l'interface lipide/eau, où elles s'adsorbent. II en résulte que les propriétés biochimiques de ces enzymes dépendent autant de la "qualité » de cette interface que des paramètres plus classiques tels que le $\mathrm{pH}$ ou la force ionique. Les activités catalytiques des lipases sont aussi étroitement dépendantes de la présence d'agents tensioactifs tels que les sels biliaires et certaines protéines alimentaires. Cette modulation peut s'exercer soit sur l'étape d'adsorption de l'enzyme à l'interface, soit sur l'étape de catalyse interfaciale.

\section{Influence de l'émulsification et des propriétés de l'émulsion}

In vivo, la dispersion des lipides sous forme de gouttelettes lipidiques permet d'augmenter l'interface lipide/eau et serait une étape clé de la lipolyse (Sarda et Desnuelle, 1958 ; Desnuelle et Benzonana, 1965). Ainsi, l'émulsification préalable des lipides alimentaires pourrait favoriser leur digestion. Des revues récentes recensent les principales études montrant comment la composition, la structure et les propriétés de l'émulsion peuvent influencer la digestion des lipides qui la constituent (Hur et al., 2011 ; Golding et Wooste, 2010 ; McClements et Li, 2010).

Dans le cas des systèmes émulsionnés, les hypothèses classiquement avancées pour expliquer I'amélioration du passage de la barrière entérocytaire (Nishimukai et al., 2003) ou de la teneur en AGPI n-3 au niveau plasmatique chez I'Homme (Garaiova et al., 2007 ; Raatz 
et al., 2009) reposent sur : i) l'existence de gouttelettes lipidiques préformées améliorant l'efficacité de la vidange gastrique chez l'Homme (Armand et al., 1994); ii) l'existence d'une interface lipide/eau préformée favorisant l'ancrage de la lipase pancréatique stabilisé par la colipase pancréatique et in fine l'hydrolyse des TAG ; iii) l'importance de la présence de PL qui modulerait l'absorption des acides gras et favoriserait chez le rat le compactage des TAG dans l'entérocyte et la libération dans la lymphe des TAG néosynthétisés (Nishimukai et al., 2003 ; Nishimukai et Hara, 2007).

La taille des gouttelettes, autrement dit le degré d'émulsification, influe également sur la digestibilité des lipides et la biodisponibilité des AG. II a en effet été montré in vitro que le taux d'hydrolyse des TAG par les lipases gastriques et pancréatiques est plus important lorsque les émulsions sont fines $(0,5 \mu \mathrm{m} v s$. $3 \mu \mathrm{m}$ ) en raison d'une plus grande surface interfaciale accessible aux enzymes (Armand et al., 1992 ; Borel et al., 1994b). Cela a été confirmé chez le rat pour des tailles de gouttelettes de 0,8 $\mu \mathrm{m}$ vs. $22 \mu \mathrm{m}$ (Borel et al., 1994a) puis chez l'Homme pour des tailles de gouttelettes de $0,7 \mu \mathrm{m}$ vs. $10 \mu \mathrm{m}$ formées à partir d'huile de poisson, $\mathrm{d}^{\prime}$ huile d'olive, de lécithine de soja ainsi que de protéines et de glucides (Armand et al., 1999). Ces auteurs ont observé un temps de vidange gastrique plus long avec des émulsions fines et en cinétique postprandiale, I'apparition des TAG plasmatiques et leur distribution vers les tissus sont retardées (Armand et al., 1999 ; Borel et al., 1994a).

La nature de l'interface est un autre paramètre important pour l'efficacité de I'hydrolyse des TAG. Pour exemple, l'addition de protéines sériques ou de caséines à l'interface de gouttelettes lipidiques améliore l'action des lipases in vitro (Armand, 2008). Mun et al. (2007) ont montré également que la lipolyse in vitro d'émulsion d'huile de colza par des lipases pancréatiques est plus importante lorsque les gouttelettes sont couvertes de protéines (protéines sériques et caséines) que lorsqu'elles sont recouvertes de PL. Des différences ont également été observées entre classes de PL. L'activité de la lipase gastrique humaine in vitro est plus élevée quand les gouttelettes sont recouvertes de phosphatidyl-choline (PC), phosphati- dyl-inositol (PI) ou phosphatidyl-sérine (PS) qu'avec des phosphatidyl-éthanolamine (PE) et sphingomyéline (SM) (Fave et al., 2007). À l'inverse, Hur et al. (2009) ont observé des effets assez faibles de la nature de l'émulsifiant lors de digestion in vitro d'émulsions, montrant la nécessité de réaliser des études in vivo pour ce type de suivi.

L'ensemble de ces études permet de conclure que l'émulsification d'une huile améliore sa digestion et I'absorption des AG. La taille et la nature de I'interface sont également des paramètres qui peuvent influencer l'absorption des lipides évaluée par la vitesse et le taux d'hydrolyse et par le temps de vidange gastrique (Singh et al., 2009). II est à noter également que les émulsions sont utilisées pour la vectorisation de micronutriments lipophiles ou de molécules actives (Ansari et al., 2008 ; McClements et al., 2007 ; McClements et al., 2009a, 2009b). Ces émulsions peuvent être incorporées dans des aliments ou utilisées en thérapeutique. Les émulsions conventionnelles sont les plus utilisées pour encapsuler des molécules lipophiles comme des acides gras oméga-3, des caroténoïdes et des phytostérols, mais des émulsions plus complexes comme des émulsions multiples ou multicouches peuvent également être utilisées (McClements et al., 2007).

D'autres suprastructures artificielles vectrices de molécules d'intérêt nutritionnel voire thérapeutique ont été développées. Dans le cas des particules lipidiques, outre les émulsions, il existe également les liposomes et les nanoparticules (Letchford et Burt, 2007 ; Wawrezinieck et al., 2008). Les liposomes sont des vésicules avec un cœur aqueux entouré d'une ou plusieurs bicouches de PL. Ils permettent donc d'encapsuler des molécules hydrophiles dans leur compartiment interne et des molécules hydrophobes dans leur membrane de PL. Pour leur utilisation en voie orale, les formulations liposomales développées sont généralement stabilisées en recouvrant la bicouche lipidique par un polymère hydrophile comme le PEG ou le chitosane (Carvalho et al., 2009 ; Klibanov et al., 1990). Les applications des liposomes en vectorisation sont très nombreuses mais ils sont principalement utilisés comme vecteurs de molécules thérapeutiques (Fenske et al., 2008 ; Torchilin, 2005 ; Takahashi et al., 2009). Quant aux nanoparticules, il en existe de plusieurs sortes. Les nanoparticules structurées réalisées à partir de nanoémulsions lipidiques mais utilisant des surfactants et cosurfactants polymériques sont de plus en plus utilisées (Anton et al., 2008 ; Huynh et al., 2009 ; Letchford et Burt, 2007). Les nanosphères sont constituées d'une matrice continue dans laquelle le principe actif est uniformément dispersé alors que les nanocapsules correspondent à des "réservoirs " où un cœur aqueux (encapsulation de molécules hydrophiles) ou huileux (encapsulation de molécules lipophiles) est entouré d'une membrane polymère (Anton et al., 2008, 2009; Huynh et al., 2009 ; Wawrezinieck et al., 2008). Certaines nanoparticules (NLC pour " nanostructured lipid carrier ") sont produites à partir d'un mélange de lipides solides et liquides (Muchow et al., 2008 ; Muller et Keck, 2004 ; Shidhaye et al., 2008). L'ensemble de ces nanoparticules lipidiques ont été utilisées pour améliorer la biodisponibilité orale de micronutriments comme des vitamines liposolubles (Iscan et al., 2005 ; Pople et Singh, 2006) et des oméga-3 (Muchow et al., 2009 ; Wallace et al., 2000) ainsi que des molécules thérapeutiques comme le paclitaxel (Peltier et al., 2006), l'ibuprofène (Lamprecht et al., 2004) et I'insuline (Sarmento et al., 2007).

\section{Influence de la structuration de la matière grasse dans les produits alimentaires}

Si des données relatives à la structuration de la matière grasse dans les principaux secteurs alimentaires sont fournies dans ce chapitre, il ressort néanmoins que la majorité des travaux reliant structuration de la matière grasse et effets physiologiques concernent à ce jour essentiellement les produits laitiers et marins.

\section{Les produits laitiers}

L'organisation de la matière grasse à l'échelle supramoléculaire a été particulièrement bien caractérisée dans le lait et les produits laitiers (Lopez, 2005 ; Lopez et Briard-Bion, 2007 ; Lopez et Gaucheron, 2008).

Dans le lait natif, les lipides forment des gouttelettes appelées globules gras (figure 2). Ces globules gras mesurent entre 0,1 et $15 \mu \mathrm{m}$ avec un diamètre moyen de $4 \mu \mathrm{m}$ et sont recouverts d'une membrane biologique spécifique (MFGM pour " milk fat globule membrane ") composée de trois couches de 
lipides polaires dans lesquelles sont inclus du cholestérol, des enzymes, des glycoprotéines et des vitamines (Keenan, 2001 ; Lopez et al., 2010 ; Lopez, 2011). Ainsi structurés, les lipides du lait (34 à $45 \mathrm{~g}$ par litre pour le lait de vache) sont représentés par $98 \%$ de TAG et $1 \%$ de phospholipides.

Au cours de la fabrication des produits laitiers, la structure des globules gras est fortement modifiée (Cousin et Michalski, 2010). L'homogénéisation du lait, appliquée systématiquement pour les laits de consommation, induit par exemple une diminution de la taille moyenne des globules gras jusqu'à $1 \mu \mathrm{m}$ de diamètre. Leur surface qui augmente, ne peut être recouverte entièrement par la MFGM. Celle-ci est complétée par d'autres agents tensioactifs présents dans le milieu, principalement des micelles de caséines. Des fragments de MFGM sont également déplacés vers la phase aqueuse sous forme de vésicules ou de liposomes tandis que les plus petits globules gras natifs ne sont pas affectés par I'homogénéisation (Michalski et al., 2002 ; Walstra, 2003). Les traitements thermiques qui accompagnent généralement l'homogénéisation dénaturent les protéines du lactosérum qui interagissent avec les protéines de la MFGM et les caséines micellaires. Les complexes caséine-protéine sérique s'adsorbent alors à l'interface des gouttelettes lipidiques (Michalski et Januel, 2006). Dans les produits laitiers tels que les fromages, les lipides peuvent se retrouver dispersés sous la forme de globules gras natifs plus ou moins agrégés ou coalescés, sous forme de globules de petite taille recouverts principalement de caséines ou sous forme d'inclusions de matière grasse libre entourées des PL issus de la MFGM (Lopez et Briard-Bion, 2007 Lopez, 2007 ; Lopez et al., 2007b, 2010). Le beurre est quant à lui une émulsion du type "eau dans huile " où les TAG constituent une phase continue partiellement cristallisée dans laquelle sont dispersées des gouttelettes de phase aqueuse (Lopez et Gaucheron, 2008).

De nombreuses études ont été réalisées dans la filière laitière pour documenter l'impact de l'organisation supramoléculaire de la matière grasse sur la digestion, I'absorption et le métabolisme des lipides (Lopez et Gaucheron, 2008; Lopez et al., 2010 ; Michalski, 2009). La modification de taille des gouttelettes lipidiques et de composition de l'inter- face peut avoir des conséquences sur la digestibilité et I'absorption des lipides. II a ainsi été montré chez les enfants prématurés que la digestibilité gastrique des globules gras de lait maternel natifs, mesurée en suivant l'hydrolyse des lipides sur des échantillons gastriques, est plus efficace que celle des globules gras homogénéisés d'une formulation infantile, malgré la plus petite taille de ces derniers (Armand et al., 1996). Berton et al. (2009) ont montré que l'efficacité catalytique de la lipase pancréatique est seulement 2 fois plus importante avec le lait homogénéisé qu'avec le lait natif, alors que la surface interfaciale est 20 fois plus importante. Cela suggère fortement qu'au-delà de la quantité d'interface, la composition et la structure de la surface des gouttelettes lipidiques joueraient un rôle clé dans la digestion des lipides. Chez le rat, Michalski et al. $(2005,2006)$ ont montré une incidence nette de l'organisation supramoléculaire de la matière grasse laitière sur l'étape digestive et le processus oxydatif postgastrique. En cinétique postprandiale, I'apparition des TAG plasmatiques est plus tardive et régulière après ingestion de crème que lorsque la même matière grasse n'est pas émulsifiée. De même l'abondance de ${ }^{13} \mathrm{CO}_{2}$ dans l'air expiré après ingestion de préparations de matière grasse contenant des TAG marqués au ${ }^{13} \mathrm{C}$, est plus régulière pour une émulsion fine (gouttelettes de $1 \mu \mathrm{m}$ recouvertes principalement de caséines) comparativement à la matière grasse non émulsionnée ou émulsifiée sous forme de grosses gouttelettes $(10 \mu \mathrm{m}$ environ) recouvertes principalement de phospholipides.

Dans les produits laitiers, les modifications d'organisation de la matière grasse et de leur environnement protéique induisent chez le rat des profils différents d'absorption lymphatique des acides gras en cinétique postprandiale (Fruekilde et Hoy, 2004). Chez I'Homme, pour des sujets sains ayant reçu pendant 3 semaines un régime où $20 \%$ de l'apport énergétique était assuré par de la matière grasse laitière sous forme de lait, de beurre ou de fromages à pâte pressée, les tests de digestion n'ont révélé aucune différence dans la quantité et la composition en acides gras des chylomicrons pendant les 8 heures de période postprandiale (Tholstrup et al., 2004). De même,
Clemente et al. (2003) ont montré pour des patients atteints de diabète de type 2 que les quantités cumulées de TAG après 6 heures de suivi en cinétique postprandiale sont similaires après consommation de beurre, de mozzarella ou de lait (30 $\mathrm{g}$ de matière grasse) mais que le beurre induit un retard du pic. Toutefois, la vitesse de vidange gastrique ne semble pas être impliquée dans ce retard. Ces résultats indiquent que la viscosité des produits et l'état de dispersion des lipides (globules gras natifs pour le lait, globules gras agrégés dans une matrice protéique pour la mozzarella, matière grasse libre pour le beurre) dans les produits laitiers influent sur la cinétique d'apparition des TAG dans le plasma. L'ensemble de ces résultats indique que l'absorption des lipides du lait est modifiée par la taille et l'interface des globules gras selon les produits. Certains résultats contradictoires sont probablement liés à la nature et la composition de la matrice et aux autres constituants des régimes qui peuvent également influer sur la lipémie postprandiale. Lopez et Gaucheron (2008) ont proposé des travaux de recherche en utilisant des matrices de composition et de structure maitrisées.

\section{Produits d'origine marine}

La teneur en TAG est extrêmement variable dans chaque tissu et selon l'état physiologique de I'animal (Fanni et al., 2004). Chez les poissons, il existe plusieurs sites de dépôt des lipides tels que le foie, le tissu adipeux périviscéral et le muscle. Le foie constitue le principal organe de stockage des lipides chez les espèces marines comme la morue. Les lipides y sont organisés sous forme de globules lipidiques voire de vacuoles après coalescence, à l'intérieur des hépatocytes et leur taille varie de 1 à $5 \mu \mathrm{m}$ en fonction de l'alimentation (Bac et al., 1983). Le tissu adipeux périviscéral est quant à lui, le site de stockage prédominant chez les salmonidés. Par ailleurs, le muscle possède des capacités à stocker les lipides variables selon les espèces, ce qui permet de distinguer notamment les poissons "maigres", comme la perche du Nil ou la sole dont la teneur en lipides dans le muscle est inférieure à $2 \%$ et les poissons gras qui ont des teneurs en lipides dans le muscle supérieures à $10 \%$ (saumon atlantique) voire $20 \%$ chez l'anguille (FontagneDicharry et Medale, 2010). 
Visioli et al. (2003) ont montré chez I'Homme qu'à quantité égale, les AGPI oméga-3 (EPA et DHA) apportés par la consommation de saumon sont mieux absorbés et incorporés dans les lipides plasmatiques que lorsqu'ils sont apportés sous forme de capsules d'esters éthyliques. Des résultats similaires ont été obtenus par Elvevoll et al. (2006) qui ont montré que les AG oméga-3 longues chaînes sont mieux incorporés dans les lipides plasmatiques lorsqu'ils sont apportés en consommant du saumon que de l'huile de foie de morue, bien que celle-ci fournisse un apport journalier en EPA+DHA trois fois plus important que le saumon. Ces résultats sont attribués à la meilleure émulsification des TAG dans la chair de poisson que dans I'huile. En revanche dans une étude plus ancienne, Cobiac et al. (1991) ont observé des effets similaires sur les lipides et les lipoprotéines plasmatiques après consommation de poisson ou d'huile de poisson par des patients hyperlipidémiques. Dans sa revue détaillée, He (2009) compare une consommation régulière de poisson et la prise de compléments alimentaires comme sources d'oméga- 3 . II souligne le rôle potentiel d'autres constituants de la chair de poisson et de l'impact de la cuisson sur la composition lipidique du poisson.

\section{Produits carnés}

Dans la viande, les TAG sont principalement stockés dans les adipocytes qui forment le tissu adipeux. Chez le porc par exemple, le lard désigne le tissu adipeux sous-cutané de la région dorsale. On retrouve également des TAG au niveau intramusculaire (figure 3), sous forme d'adipocytes en amas de petite taille contenant chacun une vésicule lipidique (vacuole). Ainsi, pour le porc, on distingue quatre catégories de dépôt: gras interne (panne), gras sous-cutané (bardière) gras intermusculaire et gras intramusculaire (persillé). Les adipocytes ont des tailles variables, selon le type de tissu adipeux et l'âge (poids) de l'animal avec par exemple $30 \mu \mathrm{m}$ pour un adipocyte isolé de tissu intramusculaire de porc âgé de 80 jours contre $50 \mu \mathrm{m}$ pour un adipocyte issu de la panne d'un porc âgé de 120 jours (Gondret, communication personnelle). Si l'on considère la teneur en lipides du muscle uniquement (le tissu adipeux étant écarté), la viande est un aliment peu gras, avec par exemple chez le porc, les teneurs extrêmes variant de 1,5\% à
$6 \%$ de lipides et en France, dans le cas des bovins, des teneurs en lipides de la plupart des morceaux n'excédant pas $6 \%$ avant cuisson (Gondret et Hocquette, 2006). Les phospholipides principalement retrouvés dans les membranes cellulaires représentent jusqu'à $1 \mathrm{~g}$ pour $100 \mathrm{~g}$ de muscle frais et sont caractérisés par la présence d'AGPI à longues chaînes, absents des TAG des mêmes animaux. La composition en acide gras des phospholipides musculaires, leurs degrés d'insaturation et les ratios oméga6/oméga-3 notamment dépendent fortement de l'alimentation des animaux et de la nature des lipides alimentaires en particulier, et ce, pour l'ensemble des espèces d'intérêt zootechnique (Gandemer, 1997, Wood et al., 2008 ; De Smet et al., 2004 ; Betti et al., 2009). La viande et les produits carnés représentent donc un apport non négligeable d'acides gras polyinsaturés dans l'alimentation. L'ensemble des produits carnés apportaient en effet selon les résultats de I'enquête SU.VI.MAX, chez les adultes français près de $21 \%$ des apports en acide linolénique, $50 \%$ de l'acide arachidonique, $16 \%$ de l'acide linolénique et $18 \%$ de l'ensemble des acides gras oméga 3 à longues chaines, dont $17 \%$ pour l'EPA, $49 \%$ pour le 22:5 n-5 et $8 \%$ pour le DHA (Astorg et al., 2004).

Dans les produits carnés transformés, et notamment dans les saucisses à pâte fine, la structure de la matière grasse est plus complexe. Les techniques mécaniques de l'affinage conduisent à une structure dispersée dans laquelle peuvent subsister des fragments de fibres musculaires et même des adipocytes, c'est-à-dire sans rupture de la membrane périphérique et donc avec conservation à l'état intact de la vacuole grasse qui en occupe l'essentiel du volume. Lorsque la vacuole grasse se vide dans le milieu continu, elle peut se diviser et apparaître sous forme de particules de tailles variables. Les techniques de microscopie notamment électronique en balayage (MEB) et en transmission (MET) révèlent deux types de structures (Katsaras et Stenzel, 1984): des vésicules grasses protégées en surface par un film interfacial de protéines solubles et des vésicules grasses non protégées, simplement emprisonnées irréversiblement à l'intérieur d'une alvéole dont la paroi protéique gélifiée assure l'étanchéité.

En ce qui concerne les produits de charcuterie française, des études relatives à la relation entre composition chimique en acides gras, en triacylglycérols et propriétés physiques (analyse thermique différentielle, diffraction des rayons $X$ ) et rhéologiques (module de rigidité en fonction de la température, ont été réalisées (CTSCCV-ACTIA, 2001).

L'essentiel des études conduites jusqu'à présent concerne uniquement les aspects technologiques et sensoriels et ne s'appuie que sur le comportement des graisses de fonte (exemple : le saindoux) qui correspondent à une pondération globale de matières grasses de carcasse. Or, ces graisses prises individuellement sont très diverses : des compositions et des structurations très variées ayant potentiellement des impacts sur le métabolisme des lipides différenciés.

\section{L'ouf}

Les lipides représentent environ les deux tiers de la matière sèche du jaune d'œuf, soit près de $6 \mathrm{~g}$ de lipides pour un œuf. Ces lipides sont majoritairement constitués de TAG (65\%) et de PL (29\%) (Anton et Gandemer, 1995). Les AG portés par les TAG représentent dans cette matière première ainsi environ $3,7 \mathrm{~g}$ pour un œuf, alors que ceux portés par les $\mathrm{PL}$ représentent environ $1,2 \mathrm{~g}$ (Pieroni et Coste, 2010). La composition en AG des lipides de I'œuf varie beaucoup selon l'alimentation des productrices, des apports significatifs en oméga-3 à longues chaînes portés par les PL pouvant être atteints (Schreiner et al., 2004 ; Baucells et al., 2000). Pieroni et Coste (2010) rapportent ainsi qu'avec un apport de graines de lin dans les aliments des poules pondeuses, un œuf peut contenir jusqu'à près de $450 \mathrm{mg}$ d'acide linolénique et $100 \mathrm{mg}$ de $\mathrm{DHA}$, des quantités allant jusqu'à $300 \mathrm{mg}$ ayant été observées pour des alimentations enrichies en huile de poisson ou en poudre d'algues.

Le jaune se présente comme une suspension de particules lipoprotéiques dans une solution de protéines. Ces particules sont principalement identifiées comme des lipoprotéines de faible densité (LDL) ou lipovitellénines et des lipoprotéines de haute densité (HDL) ou lipovitellines. Les premières ont un diamètre de l'ordre de 17 à $60 \mathrm{~nm}$. Les secondes, qui constituent les granules du jaune $d^{\prime} œ u f$ possèdent un diamètre variant de 0,2 à $2 \mu \mathrm{m}$.

Une technique de purification permet $d^{\prime}$ 'isoler par centrifugation deux fractions 
du jaune d'œuf (figure 4) : le plasma (surnageant) et les granules (culot) (Anton et al., 2001). Le plasma représente près de $60 \%$ de la matière sèche du jaune. II contient deux constituants principaux : les LDL et les livétines. Ses lipides sont constitués d'environ $70 \%$ de TAG, $25 \%$ de PL et $5 \%$ de cholestérol (Anton et Gandemer, 1995). La structure des LDL est similaire à celle des lipoprotéines sanguines : elles sont constituées d'un cœur hydrophobe formé par les TAG entourés d'une couche d'apoprotéines et de PL (figure 4). Les constituants du plasma sont très solubles dans des conditions de $\mathrm{pH}$ et de concentrations en sels courantes et confèrent au jaune d'œuf une grande part de ses propriétés émulsifiantes (Anton, 1998 ; Anton et al., 2003 ; Le Denmat et al., 2000).

Outre leur intérêt pour la structuration des aliments formulés à l'échelle colloïdale, l'attention peut être portée sur l'intérêt nutritionnel des structures lipidiques propres à l'œuf et aux ovoproduits vis-à-vis de deux types d'applications principales. La première est relative à l'apport significatif en AG oméga-3 longues chaînes localisés sur des PL (phosphatidyl-éthanolamine en particulier) qu'il peut représenter. La seconde est à lier à l'aptitude des nanostructures que constituent les lipoprotéines de l'œuf à améliorer la biodisponibilité de micro-constituants lipophiles. Ainsi, après 9 jours de test, pour des quantités ingérées similaires, la quantité de lutéine dans le sérum $\mathrm{d}^{\prime}$ adultes serait plus importante après la consommation d'œufs qu'après celle de lutéine sous forme de suppléments ou d'épinards, réputés riches en cette molécule (Chung et al., 2004).

À ces aspects, il serait possible d'ajouter le potentiel du jaune d'œuf et de ses constituants (phospholipides et antioxydants endogènes, protéines phosphorylées comme la phosvitine) à protéger les formulations de l'oxydation (Jacobsen et al., 1999).

\section{Oléagineux}

Dans les oléagineux, les lipides sont stockés dans des compartiments particuliers appelés oléosomes (figure 5) constitués d'un cœur hydrophobe de TAG entouré par une monocouche de PL et de protéines (majoritairement oléosines et caléosines) (Frandsen et al., 2001). Les lipides d'oléagineux sont majoritairement consommés sous forme $d^{\prime}$ 'huile extraite à l'état natif ou émulsionnée dans des sauces. La structure des oléosomes est détruite lors des procédés industriels classiques d'extraction. II est également possible de produire industriellement des huiles d'oléagineux riches en phospholipides par pressionextraction suivie d'un raffinage partiel sans étape de démucilagination. Ces huiles contiennent alors les PL endogènes des graines, ce qui leur confère des propriétés d'auto-émulsification. Enfin, certaines équipes ont cherché à développer de nouvelles techniques d'extraction qui préservent la structure naturelle très stable des oléosomes afin de les utiliser dans des ingrédients fonctionnels (Iwanaga et al., 2007).

\section{Effet des autres composants des matrices alimentaires}

Avant de pouvoir être digérés et absorbés, les lipides alimentaires doivent être accessibles aux enzymes digestives. Leur accessibilité peut en effet être limitée par la matrice alimentaire plus ou moins résistante et perméable dans laquelle ils se trouvent. Cette matrice, composée entre autres de protéines, de sucres, d'amidon ou de fibres, va être détruite lors de la mastication, dissoute par la salive et les sucs gastriques et digérées par les enzymes digestives, permettant ainsi la libération des lipides. La nature et la structure de la matrice alimentaire influencent donc beaucoup la biodisponibilité des lipides. Il a, par exemple, été montré que la forte résistance des parois cellulaires des noisettes limite la libération des lipides dont le taux d'absorption augmente avec une meilleure mastication (Berry et al., 2008 ; Cassady et al., 2009 ; Ellis et al., 2004).

Pour la plupart des produits alimentaires, la viscosité est fortement dépendante de la nature de la matrice. Or, plus la viscosité du bol alimentaire est importante, plus le temps de vidange gastrique est élevé et donc plus le pic des TAG plasmatiques en période postprandiale est retardé (Lopez et Gaucheron, 2008). Ceci a notamment été mis en évidence pour les produits laitiers par Fruekilde et Hoy (2004) et Sanggaard et al. (2004).

La présence de certains autres composants comme les glucides, les protéines et les minéraux peut modifier directement ou indirectement l'absorption des lipides.
Comme décrit dans la section Influence de l'émulsification et des propriétés de l'émulsion, la présence de protéines à l'interface des gouttelettes d'une émulsion artificielle améliore l'action des lipases (Armand, 2008 ; Mun et al., 2007). La nature des protéines semble également avoir une incidence. Mortensen et al. (2009) ont montré chez des patients atteints d'un diabète de type 2 que les protéines sériques diminuent plus fortement la lipémie postprandiale que la caséine, le gluten et des protéines de morue. Néanmoins, de façon générale, la présence de protéines tend à augmenter la viscosité du bol alimentaire et donc le temps de vidange gastrique, ce qui retarde le pic de lipémie postprandiale (Lopez et Gaucheron, 2008 ; Westphal et al., 2004 ; Mamo et al., 2005).

Par ailleurs, les glucides digestibles (sucres, amidon. . .) ou non (fibres) jouent un rôle important dans la digestion et l'absorption des lipides (Lairon et al., 2007). Plusieurs mécanismes ont été proposés. Tout d'abord le glucose, les oligosaccharides et certaines fibres affectent le temps de vidange gastrique (Lairon et al., 2007), ce qui pourrait expliquer le retard de la sécrétion des chylomicrons et la diminution des taux de TAG associés aux VLDL avec le glucose (Cohen et Berger, 1990 ; Westphal et al., 2002). Les fibres, en augmentant la viscosité du bol alimentaire, limitent le taux d'émulsification des lipides dans l'estomac et réduisent ainsi la lipolyse (Lairon, 1997 ; Pasquier et al., 1996) et la lipémie postprandiale (Cara et al., 1992). De plus, il a été proposé que certaines fibres aient un effet inhibiteur sur les lipases pancréatiques (Borel et al., 1989 ; Lairon et al., 1985). La présence d'amidon ne modifierait pas la lipémie postprandiale (Harbis et al., 2001). En revanche, des études cliniques ont montré que la présence de saccharose (Grant et al., 1994) et de fructose (Jeppesen et al., 1995) augmentait le taux de TAG plasmatiques après un repas riche en matière grasse.

Enfin, les AG saturés à longues chaînes libérés lors de I'hydrolyse des TAG forment avec les cations divalents alimentaires (majoritairement le calcium mais aussi de magnésium) des savons insolubles excrétés dans les selles (Guéguen et Pointillart, 2008). II a ainsi été montré chez le rat et chez l'Homme qu'une augmentation du calcium alimentaire diminue l'absorption des AG 
et augmente l'excrétion de lipides dans les selles (Bendsen et al., 2008 ; Boon et al., 2007; Lorenzen et al., 2007 ; Papakonstantinou et al., 2003 ; Shahkhalili et al., 2001). Il a également été montré que les teneurs en calcium naturellement élevées des produits laitiers limitent I'absorption des lipides et pourraient limiter la reprise de poids dans le cadre de régimes (Bendsen et al., 2008 ; Christensen et al., 2009). Toutefois, cette influence du calcium sur l'absorption des lipides dépend fortement de la structure des TAG puisque seuls les acides gras hydrolysés en position sn- 1 et sn-3 sont susceptibles de former des savons au niveau intestinal et d'être excrétés (Mattson et al., 1979 ; Nelson et al., 1996).

\section{Influence de la structure de la matiere grasse alimentaire sur l'absorption de micronutriments lipophiles}

Les micronutriments lipophiles contenus dans la matière grasse des aliments suivent le devenir des lipides dans le tube digestif. Ils sont absorbés au niveau du duodénum, sécrétés dans les chylomicrons et transportés vers le foie. Les micronutriments fortement lipophiles sont les vitamines $A, E, D$ et $K$, les caroténoïdes et les phytostérols. La présence de lipides et la structure de la matière grasse alimentaire influencent l'absorption de ces micronutriments (Borel, 2003 ; Norton et al., 2007).

Plusieurs études réalisées chez l'Homme ont montré qu'une faible quantité de lipides est nécessaire et suffisante à l'absorption des vitamines lipophiles telles que les vitamines A (Borel et al., 1997), E (Jeanes et al., 2004) et K (Gijsbers et al., 1996). Par ailleurs, la nature des AG présents semble avoir une incidence sur leur l'absorption des vitamines. Les AG à longue chaîne de I'huile d'arachide augmentent I'absorption de vitamine D (Van Den Berg, 1997) alors que la biodisponibilité de la vitamine $E$ serait plus faible lorsqu'elle est dissoute dans une huile contenant des TAG riches en AG à longue chaîne (Gallo-Torres et al., 1978; Schurgers et al., 2002). Enfin, une étude réalisée chez l'Homme par Borel et al. (2001) a montré que la taille des globules gras d'une émulsion n'a pas d'influence sur l'absorption des vitamines $\mathrm{A}$ et $\mathrm{E}$.
Comme pour les vitamines, la présence de matière grasse dans un repas améliore l'absorption des caroténoïdes, notamment des caroténoïdes d'origine végétale (Jayarajan et al., 1980 ; Ribaya-Mercado, 2002 ; Roodenburg et al., 2000). L'huile favoriserait l'extraction des caroténoïdes de sa matrice (Hedren et al., 2002). Une étude réalisée in vitro a montré que la présence de TAG affecte l'incorporation des caroténoïdes dans des micelles au cours de la digestion mais pas leur absorption par les entérocytes (Huo et al., 2007). Schweigert et al. (2000) ont montré que le type de matière grasse servant à apporter des caroténoïdes chez le rat avait une influence sur leur absorption et leur distribution dans les tissus. II a également été montré chez l'Homme que la quantité de caroténoïdes associée aux chylomicrons est plus faible en présence d'acides gras à chaîne moyenne par rapport à des acides gras à chaîne longue (Borel et al., 1998).

\section{Conclusions - De nouvelles voies d'étude}

II ressort de cette étude bibliographique que la structuration des lipides à tous les niveaux, depuis le niveau moléculaire jusqu'à leur organisation dans I'aliment, pourrait avoir des répercussions sur leur cinétique d'absorption, leur métabolisme et in fine sur la santé. Ainsi, les nouvelles études visant à améliorer les propriétés techno-fonctionnelles des matières grasses alimentaires (utilisation de TAG structurés, mélanges d'huiles...) devraient dorénavant intégrer un volet concernant leur biodisponibilité et leur impact sur la santé. Les données collectées à ce jour sont assez restreintes en ce qui concerne l'Homme. Une réflexion doit avoir lieu sur les protocoles cliniques à mettre en œuvre et les marqueurs pertinents à suivre afin de pouvoir dégager des conclusions solides. À nous de tirer parti des possibles bénéfices liés à l'organisation naturelle très complexe des matières grasses et de leurs interactions avec les autres constituants dans les aliments pour contribuer à l'équilibre alimentaire. L'émergence de nouvelles technologies pourra également servir à reproduire ces structures mais aussi à en développer de nouvelles. Des matrices aux propriétés particulières peuvent être également élaborées afin de contrôler la libération et la biodisponibilité des lipides
(McClements et al., 2008). II a par exemple été proposé d'utiliser des films composés de protéines de soja pour réguler la libération de molécules hydrophobes lors de la digestion (Chen et al., 2008). Eskins et al. (1996) et Yilmaz et al. (2001) ont décrit l'encapsulation de microgouttelettes d'huile végétale dans une matrice d'amidon. Récemment, de nombreuses innovations ont été faites dans les systèmes de vectorisation de molécules lipophiles par voie orale grâce à des particules lipidiques liquides mais aussi solides de façon à contrôler la cinétique de libération et d'absorption de composés actifs (Hauss, 2007, McClements et al., 2008; Olbrich et al., 2002). Ces études peuvent apporter des informations importantes pour mieux comprendre l'impact des propriétés de cristallisation de la matière grasse alimentaire sur la digestion et I'absorption des lipides, et pour favoriser le développement de nouvelles structures lipidiques aux propriétés particulières.

Remerciements. Les auteurs remercient I'ACTIA (Association de coordination technique pour l'industrie agroalimentaire), la DGER (ministère de I'Agriculture), le CNIEL et la région Poitou-Charentes (via le Rexcap) pour le soutien ayant permis la création de ce réseau et son fonctionnement.

Les auteurs remercient également F. Grondet, M. Anton et T. Chardot de I'Inra pour leurs illustrations ainsi qu'Odile Morin pour les données chiffrées de I'Iterg.

\section{RÉFÉRENCES}

Abrams CK, Hamosh M, Dutta SK, Hubbard VS, Hamosh P. Role of non pancreatic lipolytic activity in exocrine pancreatic insuffciency. Gastroenterology 1987 ; 92 : 125-9.

Ackman RG. Some possible effects on lipid biochemistry of differences in the distribution on glycerol of long-chain n-3 fatty acids in the fats of marine fish and marine mammals. Atherosclerosis $1988 ; 70: 171-3$.

Adam-Berret M, Rondeau-Mouro C, Riaublanc A, Mariette F. Study of triacylglycerol polymorphs by nuclear magnetic resonance: effects of temperature and chain length on relaxation parameters. Magn Reson Chem 2008 ; $46: 550-7$.

Afoakwa E, Paterson A, Fowler M, Vieira J. Influence of tempering and fat crystallization behaviours on microstructural and melting 
properties in dark chocolate systems. Food Res Int $2009 ; 42$ : 200-9.

Afssa. Avis de l'Agence française de sécurité sanitaire des aliments relatif à l'actualisation des apports nutritionnels conseillés pour les acides gras. $1^{\mathrm{er}}$ mars 2010.

Amate L, Gil A, Ramirez M. Dietary longchain PUFA in the form of TAG or phospholipids influence lymph lipoprotein size and composition in piglets. Lipids 2002 ; 37 : 975-80.

Amate L, Gil A, Ramirez M. 2001, Feeding infant piglets formula with long-chain polyunsaturated fatty acids as triacylglycerols or phospholipids influences the distribution of these fatty acids in plasma lipoprotein fractions. J Nutr $2001 ; 131$ : 1250-5.

Ansari MJ, Kohli K, Dixit N. Microemulsions as potential drug delivery systems: a review. PDA / Pharm Sci Technol 2008; 62 : 66-79.

Anton M. Structure and functional properties of hen egg yolk constituents. Recent Res Dev Agric Food Chem 1998 ; 2 : 839-64.

Anton M, Gandemer G. Composition, solubility and emulsifying properties of granules fractionated from hen egg yolk. In: VI European Symposium on the quality of Eggs and Egg Products, Zaragoza, Spain, 25-29 September, 1995 : 277-86.

Anton $M$, Martinet $V$, Dalgalarrondo $M$, Beaumal V, David-Briand E, Rabesona $H$. Chemical and structural characterisation of low-density lipoproteins purified from hen egg yolk. Food Chem $2003 ; 83$ : 17583.

Anton M, Martinet V, Tainturier D, Moussa $M$. Procédé de production d'une fraction purifiée de lipoprotéines de faible densité du jaune d'œuf et milieu de conservation incorporant de telles lipoprotéines. 2001. Brevet européen EP1223177.

Anton N, Benoit JP, Saulnier P. Design and production of nanoparticles formulated from nano-emulsion templates-a review. I Control Release 2008 ; 128 : 185-99.

Anton N, Saulnier P, Gaillard C, Porcher E, Vrignaud S, Benoit JP. Aqueous-core lipid nanocapsules for encapsulating fragile hydrophilic and/or lipophilic molecules. Langmuir 2009 ; 25 : 11413-9.

Armand M. Lipases and lipolysis in the human digestive tract: where do we stand? Curr Opin Clin Nutr 2007 ; 10 : 156-64.

Armand M. Digestibilité des matières grasses chez l'homme. Sciences des Aliments 2008 ; $28: 84-98$.

Armand $\mathrm{M}$, Borel $\mathrm{P}$, Dubois $\mathrm{C}$, et al. Characterization of emulsions and lipolysis of dietary lipids in the human stomach. Am J Physiol $1994 ; 266$ : 372-81.
Armand $\mathrm{M}$, Borel $\mathrm{P}$, Ythier $\mathrm{P}$, et al. Effects of droplet size, triacylglycerol composition, and calcium on the hydrolysis of complex emulsions by pancreatic lipase: an in vitro study. J Nutr Biochem 1992 ; 3 : 333-41.

Armand M, Hamosh M, Mehta NR, et al. Effect of human milk or formula on gastric function and fat digestion in the premature infant. Pediatr Res 1996 : 40 : 429-37.

Armand $\mathrm{M}$, Pasquier B, Andre $\mathrm{M}$, et al. Digestion and absorption of 2 fat emulsions with different droplet sizes in the human digestive tract. Am / Clin Nutr 1999; 70 : 1096-106.

Asselin G, Lavigne C, Bergeron N, et al. Fasting and postprandial lipid response to the consumption of modified milk fats by guinea pigs. Lipids 2004 ; 39 : 985-92.

Astorg P, Arnault N, Czenichow S, Noisette, N, Galan P, Hercberg S. Dietary intakes and food sources of n-6 and n-3 PUFA in French adult men and women. Lipids 2004; 39 : 527-35.

Awad T, Sato K. Acceleration of crystallisation of palm kernel oil in oil-in-water emulsion by hydrophobic emulsifier additives. Colloid Surface B $2002 ; 25$ : 45-53.

Bac N, Biagianti S, Bruslé J. Etude cytologique ultrastructurale des anomalies hépatiques du loup, de la daurade et de l'anguille, induites par une alimentation artificielle. IFREMER. In : Actes de Colloques $n$. 1. Bases biologiques de I'aquaculture. Montpellier, 1983 : 473-84.

Baucells MD, Crespo N, Barroeta AC, LopezFerrer S, Grashorn MA Incorporation of different polyunsaturated fatty acids into eggs. Poultry Sci $2000 ; 79: 51-9$.

Bendsen NT, Hother AL, Jensen SK, Lorenzen JK, Astrup A. Effect of dairy calcium on fecal fat excretion: a randomized crossover trial. Int J Obes (Lond) 2008 ; 32 : 1816-24.

Bergstedt SE, Hayashi H, Kritchevsky D, Tso P. A comparison of absorption of glycerol tristearate and glycerol trioleate by rat small intestine. Am J Physiol 1990; 259: G386-93.

Berry SE. Triacylglycerol structure and interesterification of palmitic and stearic acid-rich fats: an overview and implications for cardiovascular disease. Nutr Res Rev 2009; 22 : 3-17.

Berry SE, Miller G], Sanders TA. The solid fat content of stearic acid-rich fats determines their postprandial effects. Am J Clin Nutr 2007a ; 85 : 1486-94.

Berry SE, Sanders TA. Influence of triacylglycerol structure of stearic acid-rich fats on postprandial lipaemia. Proc Nutr Soc 2005 ; $64: 205-12$

Berry SE, Tydeman EA, Lewis HB, et al. Manipulation of lipid bioaccessibility of almond seeds influences postprandial lipemia in healthy human subjects. Am / Clin Nutr 2008 ; 88 : 922-9.

Berry SE, Woodward R, Yeoh C, Miller G], Sanders TA. Effect of interesterification of palmitic acid-rich triacylglycerol on postprandial lipid and factor VII response. Lipids 2007b ; 42 : 315-23.

Berton A., Sebban-Kreuzer C, Rouvellac S, Lopez C, Crenon I. Individual and combined action of pancreatic lipase and pancreatic lipase-related proteins 1 and 2 on native versus homogenized milk fat globules. Molecular Nutrition and Food Research 2009 ; 53 : 1-11.

Betti M, Perez TI, Zuidhof MJ, Renema RA. Omega-3-enriched broiler meat: 3. Fatty acid distribution between triacylglycerol and phospholipids classes. Poultry Sci 2009; 88 : 1740-1754.

Bonnaire L, Sandra S, Helgason T, Decker EA Weiss J, McClements DJ. Influence of lipid physical state on the in vitro digestibility of emulsified lipids. J Agric Food Chem 2008; $56: 3791-7$

Boon $\mathrm{N}$, Hul GB, Stegen $\mathrm{H}$, et al. An intervention study of the effects of calcium intake on faecal fat excretion, energy metabolism and adipose tissue mRNA expression of lipid-metabolism related proteins. Int I Obes (Lond) 2007 ; 31 : 1704-12.

Borel P. Factors affecting intestinal absorption of highly lipophilic food microconstituents (fat-soluble vitamins, carotenoids and phytosterols). Clin Chem Lab Med 2003 ; 41 : 979-94.

Borel P, Armand $\mathrm{M}$, Pasquier B, et al. Digestion and absorption of tube-feeding emulsions with different droplet sizes and compositions in the rat. J Parenter Enteral Nutr $1994 a$; $18: 534-43$

Borel P, Armand M, Ythier P, et al. Hydrolysis of emulsions with different triglycerides and droplet sizes by gastric lipase in vitro. Effect on pancreatic lipase activity. I Nutr Biochem $1994 b ; 5: 124-33$.

Borel P, Dubois C, Mekki N, et al. Dietary triglycerides, up to $40 \mathrm{~g} / \mathrm{meal}$, do not affect preformed vitamin A bioavailability in humans. Eur J Clin Nutr 1997 ; 51 : 717-22.

Borel P, Lairon D, Senft M, Chautan M, Lafont $\mathrm{H}$. Wheat bran and wheat germ: effect on digestion and intestinal absorption of dietary lipids in the rat. Am / Clin Nutr 1989; 49 : 1192-202.

Borel $\mathrm{P}$, Pasquier $\mathrm{B}$, Armand $\mathrm{M}$, et al. Processing of vitamin $A$ and $E$ in the human gastrointestinal tract. Am / Physiol Gastrointest Liver Physiol 2001 ; 280 : G95-G103.

Borel P, Tyssandier V, Mekki N, et al. Chylomicron beta-carotene and retinyl pal- 
mitate responses are dramatically diminished when men ingest beta-carotene with medium-chain rather than long-chain triglycerides. J Nutr $1998 ; 128$ : 1361-7.

Bottino NR, Vandenburg GA, Reiser R. Resistance of certain long-chain polyunsaturated fatty acids of marine oils to pancreatic lipase hydrolysis. Lipids $1967 ; 2$ : 489-93.

Boulos P, Combe N. Biodisponibilité de l'acide $\alpha$-linolénique : intérêt $d^{\prime}$ 'une huile combinée.Oleaginaux Corps Gras Lipides $2000 ; 7: 101-4$

Bourre JM. Alimentation animale et valeur nutritionnelle induite sur les produits dérivés consommés par l'homme : Les lipides sontils principalement concernés? Oléagineux, Corps Gras, Lipides 2003 ; 10 : 405-24.

Bracco U. Effect of triglyceride structure on fat absorption. Am / Clin Nutr 1994; 60 : 1002S-9S.

Braipson-Danthine S, Gibon V. Comparative analysis of triacylglycerol composition, melting properties and polymorphic behavior of palm oil and fractions. Eur J Lipid Sci Technol 2007 ; 109 : 359-72.

Buchanan B, Gruissem W, Jones R. Biochemistry \& Molecular Biology of Plants. Rockville : ASPP 2000.

Bunea R, El Farrah K, Deutsch L. Evaluation of the effects of Neptune Krill Oil on the clinical course of hyperlipidemia. Altern Med Rev $2004 ; 9$ : 420-8.

Campbell S, Goff H, Rousseau D. Comparison of crystallization properties of a palm stearin/ canola oil blend and lard in bulk and emulsified form. Food Res Int 2002; 35 : 935-44.

Cansell M. Impact de la cristallisation des corps gras sur les propriétés des produits finis. Oléagineux, Corps Gras, Lipides 2005 ; 12 : 427-31.

Cansell MS, Battin A, Degrace P, Gresti J, Clouet $P$, Combe N. Early dissimilar fates of liver eicosapentaenoic acid in rats fed liposomes or fish oil and gene expression related to lipid metabolism. Lipids 2009 ; 44 : 237-47.

Cansell M, Moussaoui N, Petit AP, Denizot A, Combe N. Feeding rats with liposomes or fish oil differently affects theirlipid metabolism. Eur J Lipid Sci Technol 2006 ; 108 : 45967.

Cansell M, Nacka F, Combe N. Marine lipidbased liposomes increase in vivo FA bioavailability. Lipids 2003 ; 38 : 551-9.

Cara $L$, Dubois $C$, Borel $P$, et al. Effects of oat bran, rice bran, wheat fiber, and wheat germ on postprandial lipemia in healthy adults. Am J Clin Nutr $1992 ; 55: 81-8$.

Carnielli VP, Verlato G, Pederzini F, et al. Intestinal absorption of long-chain polyunsaturated fatty acids in preterm infants fed breast milk or formula. Am J Clin Nutr 1998 ; 67 : 97-103.

Carrière F. Soixante ans de recherche sur la lipolyse enzymatique ds corps gras à Marseille.Oleagineux Corps Gras Lipides 2008 ; 15 : 196-207.

Carvajal O, Sakono M, Sonoki $\mathrm{H}$, et al. Structured triacylglycerol containing mediumchain fatty acids in sn-1(3) facilitates the absorption of dietary long-chain fatty acids in rats. Biosci Biotechnol Biochem 2000; 64 : 793-8.

Carvalho EL, Grenha A, Remunan-Lopez C, Alonso MJ, Seijo B. Mucosal delivery of liposome-chitosan nanoparticle complexes. Methods Enzymol 2009 ; 465 : 289-312.

Cassady BA, Hollis JH, Fulford AD, Considine RV, Mattes RD. Mastication of almonds: effects of lipid bioaccessibility, appetite, and hormone response. Am J Clin Nutr 2009 ; 89 : 794-800.

Chardigny JM, Masson E, Sergiel JP, et al. The position of rumenic acid on triacylglycerols alters its bioavailability in rats. J Nutr 2003 ; $133: 4212-4$.

Che Man YB, Haryati T, Ghazali HM, Asbi BA. Composition and thermal profile of crude palm oil and its products. I Am Oil Chem Society $1999 ; 76$ : 237-42.

Chen L, Remondetto G, Rouabhia M, Subirade $M$. Kinetics of the breakdown of crosslinked soy protein films for drug delivery. Biomaterials 2008 ; 29 : 3750-6.

Christensen MS, Høy CE. Effects of dietary triacylglycerol structure on triacylglycerols of resultant chylomicrons from fish oil- and seal oil-fed rats. Lipids 1996 ; 31 : 341-4.

Christensen MS, Hoy CE, Becker CC, Redgrave TG. Intestinal absorption and lymphatic transport of eicosapentaenoic (EPA), docosahexaenoic (DHA), and decanoic acids : dependence on intramolecular triacylglycerol structure. Am J Clin Nutr 1995 ; 61 : 56-61.

Christensen MS, Hoy CE, Redgrave TG. Lymphatic absorption of $n-3$ polyunsaturated fatty acids from marine oils with different intramolecular fatty acid distributions. Biochim Biophys Acta 1994 ; 1215 : 198-204.

Christensen R, Lorenzen JK, Svith CR, et al. Effect of calcium from dairy and dietary supplements on faecal fat excretion : a metaanalysis of randomized controlled trials. Obes Rev $2009 ; 10: 475-86$.

Christophe AB, De Greyt WF, Delanghe JR, Huyghebaert AD. Substituting enzymatically interesterified butter for native butter has no effect on lipemia or lipoproteinemia in Man. Ann Nutr Metab 2000 ; 44 : 61-7.

Chung HY, Rasmussen HM, Johnson EJ. Lutein bioavailability is higher from luteinenriched eggs than from supplements and spinach in men. J Nutr 2004; 134 : 1887-93.

Clemente G, Mancini M, Nazzaro F, et al. Effects of different dairy products on postprandial lipemia. Nutr Metab Cardiovasc Dis $2003 ; 13: 377-83$.

Cobiac L, Clifton PM, Abbey M, Belling GB, Nestel PJ. Lipid, lipoprotein, and hemostatic effects of fish vs fish-oil n-3 fatty acids in mildly hyperlipidemic males. Am / Clin Nutr $1991 ; 53$ : 1210-6.

Cohen JC, Berger GM. Effects of glucose ingestion on postprandial lipemia and triglyceride clearance in humans. J Lipid Res $1990 ; 31$ : 597-602.

Combe N, Boue-Vaysse C. Face aux besoins et à la réalité des consommations, quelles sont les spécificités des différentes sources d'acides gras oméga 3 disponibles ? Oléagineux, Corps Gras, Lipides 2004 ; 11 : 103-5.

Corredig M, Roesch RR, Dalgleish DG. Production of a novel ingredient from buttermilk. J Dairy Sci 2003 ; 86 : 2744-50.

Coupland J. Crystallization in emulsions. Curr Opin Colloid Interface Sci 2002; 7 : 445-50.

Cousin O, Michalski MC. À I'usine - Préparation du lait. Sciences des Aliments $2010 ; 29$ : 21-33.

Crockett ME, Deuel HJ. A Comparison of the Coefficient of Digestibility and the Rate of Absorption of Several Natural and Artificial Fats as Influenced by Melting Point. / Nutr $1947 ; 33: 187-94$.

CTSCCV (Centre Technique de la Salaison, de la Charcuterie et des Conserves de Viandes). Microstructure des émulsions et dispersions alimentaires. Projet ACTIA RA 96-08, 2001.

De Fouw NJ, Kivits GA, Quinlan PT, Van Nielen WG. Absorption of isomeric, palmitic acid-containing triacylglycerols resembling human milk fat in the adult rat. Lipids $1994 ; 29$ : 765-70.

De Schrijver R, Vermeulen D, Backx S. Digestion and absorption of free and esterified fish oil fatty acids in rats. Lipids 1991a ; $26: 400-4$.

De Schrijver R, Vermeulen D, Viaene E. Lipid metabolism responses in rats fed beef tallow, native or randomized fish oil and native or randomized peanut oil. J Nutr 1991b ; 121 : 948-55.

De Smet S, Raes K, Demeyr D. Meat fatty acid composition as affected by fatness and genetic factors: a review. Anim Res 2004; $53: 81-98$.

Decker EA. The role of stereospecific saturated fatty acid positions on lipid nutrition. Nutrition Reviews 1996 ; 54 : 108-10.

Desnuelle P, Benzonana G. Kinetic study of the action of pancreatic lipase on emulsified 
triglycerides. Enzymology assay in heterogeneous medium. Biochimica et Biophysica Acta $1965 ; 105: 121-36$.

Dewettinck K, Rombaut R, Thienpont N, Le TT, Messens K, Van Camp J. Nutritional and technological aspects of milk fat globule membrane material. Int Dairy / 2008 ; 18 : 436-57.

Ellis PR, Kendall CW, Ren Y, et al. Role of cell walls in the bioaccessibility of lipids in almond seeds. Am J Clin Nutr 2004; 80 : 604-13.

Elvevoll EO, Barstad $\mathrm{H}$, Breimo ES, et al. Enhanced incorporation of n-3 fatty acids from fish compared with fish oils. Lipids 2006 ; 41 : 1109-14.

Eskins K, Fanta G, Felker F, Baker F. Ultrastructural studies on microencapsulated oil droplets in aqueous gels and dried films of a new starch-oil composite. Carbohydrate Polymers 1996 ; 29 : 233-9.

Fanni J, Linder M, Parmentier M. Lipides polaires marins. Oléagineux, Corps Gras, Lipides $2004 ; 11$ : 142-5.

Fave G, Leveque C, Peyrot J, Pieroni G, Coste TC, Armand M. Modulation of gastric lipolysis by the phospholipid specie : link to specific lipase-phospholipid interaction at the lipid/water interface? FASEB / 2007; 21: A1010-a-.

Fenske DB, Chonn A, Cullis PR. Liposomal nanomedicines: an emerging field. Toxicol Pathol $2008 ; 36: 21-9$.

Finley J, Klemann L, Leveille G, Otterburn M, Walchak C. Caloric availability of Salatrim in rats and humans: A potential low-calorie fat substitute. J Agric Food Chem 1994a; 42 : 495-9.

Finley J, Leveille G, Dixon R, et al. Clinical assessment of Salatrim, a reduced-calorie triacylglycerol. J Agric Food Chem 1994b; 42 : 581-96.

Fontagne-Dicharry S, Medale F. Les lipides des poissons d'aquaculture et leurs facteurs de variation. Oléagineux, Corps Gras, Lipides 2010 ; 17 : 209-13.

Frandsen GI, Mundy J, Tzen JT. Oil bodies and their associated proteins, oleosin and caleosin. Physiol Plant $2001 ; 112$ : 301-7.

Fruekilde MB, Hoy CE. Lymphatic fat absorption varies among rats administered dairy products differing in physiochemical properties. J Nutr 2004 ; 134 : 1110-3.

Gallo-Torres HE, Ludorf J, Brin M. The effect of medium-chain triglycerides on the bioavailability of vitamin E. Int / Vitam Nutr Res 1978 ; $48: 240-1$.

Gandemer G. Lipides du muscle et qualité de la viande. Phospholipides et flaveur. Oléagineux, Corps Gras, Lipides 1997 ; 4 : 19-25.
Garaiova I, Guschina IA, Plummer SF, Tang J, Wang D, Plummer NT. A randomised crossover trial in healthy adults indicating improved absorption of omega- 3 fatty acids by preemulsification. Nutr J $2007 ; 6: 4$.

Garbolino C, Bartoccini M, Flöter E. The influence of emulsifiers on the crystallisation behaviour of a palm oil-based blend. Eur I Lipid Sci Technol 2005 ; 107 : 616-26.

Gargouri Y, Pieroni G, Riviere C, et al. Kinetic assay of human gastric lipase on short- and long-chain triacylglycerol emulsions. Gastroenterology $1986 ; 91$ : 919-25.

Genot C, Michalski MC. Impact métabolique des structures et de l'oxydation des lipides dans les aliments. Innovations Agronomiques 2010 : 43-67.

Gijsbers BL, Jjie KS, Vermeer C. Effect of food composition on vitamin $\mathrm{K}$ absorption in human volunteers. Br J Nutr 1996 ; 76 : 223-9.

Gnädig S, Chardigny JM, Sébédio JL. Lipides. In : G. Debry (ed.), Lait, nutrition et santé. Paris : Tec\&Doc Editions, 2001.

Golding M, Wooste TJ. The infuence of emulsion structure and stability on lipid digestion. Current Opinion in Colloid \& Interface Science $2010 ; 15$ : 90-101.

Grant KI, Marais MP, Dhansay MA. Sucrose in a lipid-rich meal amplifies the postprandial excursion of serum and lipoprotein triglyceride and cholesterol concentrations by decreasing triglyceride clearance. Am / Clin Nutr $1994 ; 59: 853-60$.

Gondret F, Hocquette J-F. La teneur en lipides de la viande: une balance métabolique complexe. Prod. Anim 2006 ; 19 : 327-38.

Guéguen L, Pointillart A. Interactions digestives et métaboliques entre lipides et calcium. Sciences des Aliments 2008 ; 28 : 117-27.

Hamazaki T, Urakaze M, Makuta $M$, et al. Intake of different eicosapentaenoic acidcontaining lipids and fatty acid pattern of plasma lipids in the rats. Lipids $1987 ; 22$ : 994-8.

Hamosh M. Lingual and gastric lipases. Nutr $1990 ; 6: 421-8$.

Hamosh M, Bitman J, Wood L, Hamosh P, Mehta NR. Lipids in milk and the first steps in their digestion. Pediatrics 1985 ; $75: 146-50$.

Hanahan DJ 1997. A Guide to Phospholipid Chemistry. New York: Oxford University Press, $1997: 214$.

Hara K, Onizawa K, Honda H, Otsuji K, Ide T, Murata M. Dietary diacylglycerol-dependent reduction in serum triacylglycerol concentration in rats. Ann Nutr Metab 1993; 37 : 185-91.

Harbis A, Defoort C, Narbonne H, et al. Acute hyperinsulinism modulates plasma apolipo- protein B-48 triglyceride-rich lipoproteins in healthy subjects during the postprandial period. Diabetes 2001 ; 50 : 462-9.

Hauss D J. Oral lipid-based formulations. $A d v$ Drug Deliv Rev 2007 ; 59 : 667-76

He K. Fish, long-chain omega-3 polyunsaturated fatty acids and prevention of cardiovascular disease-eat fish or take fish oil supplement? Prog Cardiovasc Dis 2009; 52 : 95-114.

Hedren E, Diaz V, Svanberg U. Estimation of carotenoid accessibility from carrots determined by an in vitro digestion method. Eur J Clin Nutr $2002 ; 56:$ 425-30.

Himawan C, Starov VM, Stapley AG. Thermodynamic and kinetic aspects of fat crystallization. Adv Colloid Interface Sci 2006 ; $122: 3-33$.

Hunter JE. Studies on effects of dietary fatty acids as related to their position on triglycerides. Lipids 2001 ; 36 : 655-668.

Huo T, Ferruzzi MG, Schwartz SJ, Failla ML. Impact of fatty acyl composition and quantity of triglycerides on bioaccessibility of dietary carotenoids. J Agric Food Chem 2007 ; 55 : 8950-7.

Hur SJ, Decker E, McClements D. Influence of initial emulsifier type on microstructural changes occurring in emulsified lipids during in vitro digestion. Food Chem 2009; 114 : 253-62.

Hur SJ, Lim BO, Decker EA, McClements DJ. In vitro human digestion models for food applications. Food Chem $2011 ; 125$ : 1-12.

Huynh NT, Passirani C, Saulnier P, Benoit JP. Lipid nanocapsules: a new platform for nanomedicine. Int / Pharm 2009; 379 : 201-9.

Ikeda I. Digestion and Absorption of Structured Lipids. In: T.A.O.C. Society (Eds.), Fat digestion and absorption. 2000 : 235-42.

Ikeda I, Imasato $\mathrm{Y}, \mathrm{Nagao} \mathrm{H}$, et al. Lymphatic transport of eicosapentaenoic and docosahexaenoic acids as triglyceride, ethyl ester and free acid, and their effect on cholesterol transport in rats. Life Sci $1993 ; 52$ : 1371-9.

Ikeda I, Sasaki E, Yasunami H, et al. Digestion and lymphatic transport of eicosapentaenoic and docosahexaenoic acids given in the form of triacylglycerol, free acid and ethyl ester in rats. Biochim Biophys Acta $1995 ; 1259$ : 297-304.

Innis SM, Dyer RA, Lien EL. Formula containing randomized fats with palmitic acid (16:0) in the 2-position increases $16: 0$ in the 2 position of plasma and chylomicron triglycerides in formula-fed piglets to levels approaching those of piglets fed sow's milk. J Nutr 1997 ; 127 : 1362-70. 
Innis SM, Dyer R, Nelson CM. Evidence that palmitic acid is absorbed as sn-2 monoacylglycerol from human milk by breast-fed infants. Lipids $1994 ; 29$ : 541-5.

Innis SM, Dyer R, Quinlan P, Diersen-Schade D. Palmitic acid is absorbed as sn-2 monopalmitin from milk and formula with rearranged triacylglycerols and results in increased plasma triglyceride sn- 2 and cholesteryl ester palmitate in piglets. I Nutr $1995 ; 125: 73-81$.

Iscan Y, Wissing SA, Hekimoglu S, Muller RH. Solid lipid nanoparticles (SLN) for topical drug delivery: incorporation of the lipophilic drugs $\mathrm{N}, \mathrm{N}$-diethyl-m-toluamide and vitamin K. Pharmazie 2005 ; 60 : 905-9.

Iwanaga D, Gray DA, Fisk ID, Decker EA, Weiss J, McClements DJ. Extraction and characterization of oil bodies from soy beans: a natural source of pre-emulsified soybean oil. J Agric Food Chem 2007 ; 55 : 8711-6.

Jacobsen C, Adler-Nissen J, Meyer AS. Effect of ascorbic acid on iron release from the emulsifier interface and on the oxidative flavor deterioration in fish oil enriched mayonnaise. J Agric Food Chem 1999; 47 : 4917-26.

Jandacek RJ, Kester JJ, Papa AJ, Wehmeier TJ, Lin PY. Olestra formulation and the gastrointestinal tract. Lipids 1999 ; 34 : 771-83.

Jandacek RJ, Whiteside JA, Holcombe BN, Volpenhein RA, Taulbee JD. The rapid hydrolysis and efficient absorption of triglycerides with octanoic acid in the 1 and 3 positions and long-chain fatty acid in the 2 position. Am / Clin Nutr 1987; 45 : 940-5.

Jayarajan P, Reddy V, Mohanram M. Effect of dietary fat on absorption of beta carotene from green leafy vegetables in children. Indian J Med Res 1980 ; 71 : 53-6.

Jeanes YM, Hall WL, Ellard S, Lee E, Lodge JK. The absorption of vitamin $E$ is influenced by the amount of fat in a meal and the food matrix. Br J Nutr 2004 ; 92 : 575-9.

Jeppesen J, Chen YI, Zhou MY, Schaaf P, Coulston A, Reaven GM. Postprandial triglyceride and retinyl ester responses to oral fat: effects of fructose. Am / Clin Nutr 1995 ; $61:$ 787-91.

Judde A, Villeneuve P, Rossignol-Castera A, le Guillou A. Antioxidant effect of soy lecithins on vegetable oil stability and their synergism with tocopherols. I Am Oil Chem Soc 2003 ; $80: 1209-15$

Kalnin D, Garnaud G, Amenitsch H, Ollivon M. Monitoring fat crystallization in aerated food emulsions by combined DSC and timeresolved synchrotron X-ray diffraction. Food Res Int 2002 ; 35 : 927-34.
Kalnin D, Lesieur P, Artzner F, Keller G, Ollivon M. Systematic investigation of lard polymorphism using combined DSC and time-resolved synchrotron X-ray diffraction. Eur J Lipid Sci Technol 2005 ; 107 : 594-606.

Katsaras K, Stenzel R. Beobachtungen der Brühwurst-Mikrostrutur mit dem Raster-undtransmissions-Elektronenmikroskop. Fleischwirtsch $1984 ; 64$ : 951-7.

Keenan TW. Milk lipid globules and their surrounding membrane: a brief history and perspectives for future research. I Mammary Gland Biol Neoplasia 2001; 6 : 365-71.

Kidd P. M. Omega-3 DHA and EPA for cognition, behavior, and mood: clinical findings and structural-functional synergies with cell membrane phospholipids. Altern Med Rev 2007 ; 12 : 207-27.

Kindel T, Lee DM, Tso P. The mechanism of the formation and secretion of chylomicrons. Review Article. Atherosclerosis Supplements 2010 ; $11: 11-16$.

Klibanov AL, Maruyama K, Torchilin VP, Huang L. Amphipathic polyethyleneglycols effectively prolong the circulation time of liposomes. FEBS Lett $1990 ; 268$ : 235-7.

Kritchevsky D, Tepper S, Kuksis A, Eghtedary $\mathrm{K}$, Klurfeld D. Cholesterol vehicle in experimental atherosclerosis. 21. Native and randomized lard and tallow. J Nutr Biochem 1998 a ; 9 : 582-5.

Kritchevsky D, Tepper S, Kuksis A, Wright S, Czarnecki S. Cholesterol vehicle in experimental atherosclerosis. 22. Refined, bleached, deodorized (RBD) palm oil, randomized palm oil and red palm oil. Nutr Res 2000a ; $20: 887-92$.

Kritchevsky D, Tepper S, Wright S, Kuksis A, Eghtedary K, Hughes T. Cholesterol vehicle in experimental atherosclerosis. 20. Cottonseed oil and randomized cottonseed oil. Nutr Res $1998 \mathrm{~b} ; 18$ : 259-64.

Krokan HE, Bjerve KS, Mork E. The enteral bioavailability of eicosapentaenoic acid and docosahexaenoic acid is as good from ethyl esters as from glyceryl esters in spite of lower hydrolytic rates by pancreatic lipase in vitro. Biochim Biophys Acta 1993; 1168 : 59-67.

Kubow S. The influence of positional distribution of fatty acids in native, interesterified, and structure-specific lipids on lipoprotein metabolism and atherogenesis. I Nutr Biochem 1996 ; 7 : 530-41.

Kuksis A. Yolk lipids. Biochim Biophys Acta $1992 ; 1124$ : 205-22.

Lagarde M, Bernoud N, Brossard N, et al. Lysophosphatidylcholine as a preferred carrier form of docosahexaenoic acid to the brain. J Mol Neurosci 2001 ; 16 : 201-4 ; discussion 215-21.

Lagarde M, Guichardant M, Picq M, Michaud $S$, Doutheau A. Procédé de préparation d'acétyl, docosahexaénoyl-glycérophosphocholine, et son utilisation pour l'apport d'acides gras polyinsaturés. France, 2009.

Lai HC, Ney DM. Gastric digestion modifies absorption of butterfat into lymph chylomicrons in rats. J Nutr 1998; 128 : 2403-10.

Lai HC, Lasekan JB, Monsma CC, Ney DM. Alteration of plasma lipids in the rat by fractionation of modified milk fat (butterfat). J Dairy Sci 1995 ; 78 : 794-803.

Lairon D. Soluble fibers and dietary lipids. $A d v$ Exp Med Biol 1997 ; 427 : 99-108.

Lairon D, Lafont H, Vigne JL, Nalbone G, Leonardi J, Hauton JC. Effects of dietary fibers and cholestyramine on the activity of pancreatic lipase in vitro. Am / Clin Nutr 1985 ; 42 : 629-38.

Lairon D, Lopez-Miranda J, Williams C. Methodology for studying postprandial lipid metabolism. Eur J Clin Nutr 2007a; 61 : 1145-61.

Lairon D, Play B, Jourdheuil-Rahmani D. Digestible and indigestible carbohydrates: interactions with postprandial lipid metabolism. J Nutr Biochem 2007 ; 18 : 217-27.

Lamprecht A, Saumet JL, Roux J, Benoit JP. Lipid nanocarriers as drug delivery system for ibuprofen in pain treatment. Int I Pharm 2004 ; 278 : 407-14.

Lawson KD, Middleton SJ, Hassall CD. Olestra, a nonabsorbed, noncaloric replacement for dietary fat: a review. Drug Metab Rev $1997 ; 29: 651-703$.

Lawson LD, Hughes BG. Human absorption of fish oil fatty acids as triacylglycerols, free acids, or ethyl esters. Biochem Biophys Res Commun $1988 ; 152$ : 328-35.

Le Denmat $M$, Anton $M$, Beaumal V. Characterisation of emulsion properties and of interface composition in O/W emulsions prepared with hen egg yolk, plasma and granules. Food Hydrocolloids 2000; 14 : 539-49.

Letchford K, Burt $\mathrm{H}$. A review of the formation and classification of amphiphilic block copolymer nanoparticulate structures: micelles, nanospheres, nanocapsules and polymersomes. Eur J Pharm Biopharm 2007; 65 : 259-69.

Lien EL. The role of fatty acid composition and positional distribution in fat absorption in infants. J Pediatr $1994 ; 125$ : S62-8.

Lien EL, Yuhas RJ, Boyle FG, Tomarelli RM. Corandomization of fats improves absorption in rats. J Nutr $1993 ; 123$ : 1859-67. 
Livesey $\mathrm{G}$. The absorption of stearic acid from triacylglycerols: an inquiry and analysis. Nutr Res Rev $2000 ; 13$ : 185-214.

Loisel C, Keller G, Lecq G, Bourgaux C, Ollivon M. Phase transition and polymorphism of cocoa butter. I Am Oil Chem Soc 1998 ; 75 : 425-39.

Lopez C. Focus on the supramolecular structure of milk fat in dairy products. Reprod Nutr Dev 2005 ; 45 : 497-511.

Lopez C. Milk fat globules enveloped by their biological membrane: unique colloidal assemblies with a specific composition and structure. Currt Opin Colloid In (accepté pour publication le 31/05/2011; DOI = 10.1016/j. cocis.2011.05.007).

Lopez C, Bourgaux C, Lesieur P, Ollivon M. Coupling of time-resolved synchrotron $\mathrm{X}$-ray diffraction and DSC to elucidate the crystallisation properties and polymorphism of triglycerides in milk fat globules. Lait 2007a ; 87 : 459-80.

Lopez C, Bourgaux C, Lesieur P, Bernadou S, Keller G, Ollivon M. Thermal and structural behavior of milk fat. 3. Influence of cooling rate and droplet size on cream crystallization. J Colloid Interface Sci 2002; 254 : 64-78.

Lopez C, Briard-Bion V. The composition, supramolecular organisation and thermal properties of milk fat: a new challenge for the quality of food products. Lait $2007 ; 87$ : 317-36.

Lopez C, Briard-Bion V, Beaucher E, Ollivon M. Multiscale characterization of the organization of triglycerides and phospholipids in emmental cheese: from the microscopic to the molecular level. J Agric Food Chem 2008 ; $56: 2406-14$.

Lopez C, Briard-bion V, Camier B, Gassi JY. Milk fat thermal properties and solid fat content in emmental cheese : a differential scanning calorimetry study. J Dairy Sci 2006 ; 89 : 2894-910.

Lopez C, Camier B, Gassi JY. Development of the milk fat microstructure during the manufacture and ripening of Emmental cheese observed by confocal laser scanning microscopy. Int Dairy J 2007b ; 17 : 235-47.

Lopez C, Gaucheron F. Qualité nutritionnelle des produits laitiers : effets de la composition et de la suprastructure des lipides et rôle des autres constituants de la matrice sur la digestion et l'absorption des acides gras. Sciences des Aliments 2008 ; 28 : 106-16.

Lopez C, Karray N, Lesieur P, Ollivon M. Crystallisation and melting properties of dromedary milk fat globules studied by Xray diffraction and differential scanning calorimetry. Comparison with anhydrous dromedary milk fat. Eur J Lipid Sci Technol $2005 ; 107: 673-83$.
Lopez C, Le Ruyet P, Quiblier JP. Matière grasse laitière dans les fromages affiniés: Effets de sa composition, de sa structure et des autres constituants de la matrice sur sa digestion et conséquences métaboliques. Sciences des Aliments 2010; 29: 69. 87.

Lopez C, Lesieur P, Keller G, Ollivon M. Thermal and Structural Behavior of Milk Fat: 1. Unstable Species of Cream. / Colloid Interface Sci $2000 ; 229$ : 62-71.

Lopez C, Madec MN, Jimenez-Flores R. Presence of lipid rafts in the bovine milk fat globule membrane revealed by the lateral segregation of phospholipids and heterogeneous distribution of glycoproteins. Food chem $2010 ; 120$ : 22-33.

Lopez C, Ollivon M. Crystallisation of triacylglycerols in nanoparticles, Effect of dispersion and polar lipids. J Therm Anal Calorim 2009a ; 98 : 29-37.

Lopez C, Ollivon M. Triglycerides obtained by dry fractionation of milk fat: 2 . Thermal properties and polymorphic evolutions on heating. Chem Phys Lipids 2009b; $159: 1-12$.

Lorenzen JK, Nielsen S, Holst JJ, Tetens I, Rehfeld JF, Astrup A. Effect of dairy calcium or supplementary calcium intake on postprandial fat metabolism, appetite, and subsequent energy intake. Am / Clin Nutr 2007 ; $85: 678-87$.

Lucas A, Quinlan P, Abrams S, Ryan S, Meah $S$, Lucas PJ. Randomised controlled trial of a synthetic triglyceride milk formula for preterm infants. Arch Dis Child Fetal Neonatal Ed 1997 ; 77: F178-84.

Lund AP, Tholstrup T. The nutritional importance of milk phospholipids. Maelkeritidende 2004 ; 117 : 11-6.

Maki KC, Mustad V, Dicklin MR, Geohas J. Postprandial metabolism with 1,3-diacylglycerol oil versus equivalent intakes of longchain and medium-chain triacylglycerol oils. Nutrition 2009 ; 25 : 627-33.

Mamo JC, James AP, Soares MJ, Griffiths DG, Purcell K, Schwenke JL. A low-protein diet exacerbates postprandial chylomicron concentration in moderately dyslipidaemic subjects in comparison to a lean red meat protein-enriched diet. Eur J Clin Nutr 2005 ; $59: 1142-8$.

Martin D, Reglero G, Senorans FJ. Oxidative stability of structured lipids. Eur Food Res Technol $2010 ; 231:$ 635-53.

Mathews SA, Oliver WT, Phillips OT, Odle J, Diersen-Schade DA, Harrell RJ. Comparison of triglycerides and phospholipids as supplemental sources of dietary long-chain polyunsaturated fatty acids in piglets. I Nutr $2002 ; 132$ : 3081-9.
Mattson FH, Nolen GA, Webb MR. The absorbability by rats of various triglycerides of stearic and oleic acid and the effect of dietary calcium and magnesium. I Nutr $1979 ; 109:$ 1682-7.

McClements DJ, Decker EA, Weiss J. Emulsion-based delivery systems for lipophilic bioactive components. J Food Sci 2007; 72 : R109-24.

McClements DJ, Decker EA, Park Y. Controlling lipid bioavailability through physicochemical and structural approaches. Crit Rev Food Sci Nutr 2009a ; 49 : 48-67.

McClements DJ, Decker EA, Park Y, Weiss J. Designing food structure to control stability, digestion, release and absorption of lipophilic food components. Food Biophysics $2008 ; 3$ : 219-28.

McClements DJ, Decker EA, Park Y, Weiss J. Structural design principles for delivery of bioactive components in nutraceuticals and functional foods. Crit Rev Food Sci Nutr 2009b ; 49 : 577-606.

McClements DJ, Li Y. Structured emulsionbased delivery systems: controlling the digestion and release of lipophilic food components. Adv Colloid Interfac 2010; 159: 213-28.

Meijer GW, Weststrate JA. Interesterification of fats in margarine : effect on blood lipids, blood enzymes, and hemostasis parameters. Eur J Clin Nutr 1997 ; 51 : 527-34.

Michalski MC. Structure des triglycérides de la matière grasse laitière et facteurs de risque cardiovasculaire. Sciences des aliments 2008 ; $28: 150-5$.

Michalski MC. Specific molecular and colloidal structures of milk fat affecting lipolysis, absorption and postprandial lipemia. Eur J Lipid Sci Technol 2009 ; 111 : 413-31.

Michalski MC, Briard V, Desage M, Geloen A. The dispersion state of milk fat influences triglyceride metabolism in the rat-a $13 \mathrm{CO} 2$ breath test study. Eur / Nutr 2005 ; 44 : 43644.

Michalski MC, Januel C. Does homogenization affect the human health properties of cow's milk? Trends Food Sci Technol 2006 ; 17 : 423-37.

Michalski MC, Michel F, Geneste C. Appearance of submicronic particles in the milk fat globule size distribution upon mechanical treatments. Lait 2002; 82 : 193-208.

Michalski MC, Ollivon M, Briard V, Leconte $\mathrm{N}$, Lopez C. Native fat globules of different sizes selected from raw milk: thermal and structural behavior. Chem Phys Lipids 2004 ; 132 : 247-61.

Michalski MC, Soares AF, Lopez C, Leconte $\mathrm{N}$, Briard V, Geloen A. The supramolecular 
structure of milk fat influences plasma triacylglycerols and fatty acid profile in the rat. Eur J Nutr 2006 ; 45 : 215-24.

Moreau H, Gargouri Y, Lecat D, Junien JL, Verger R. Purification, characterization and kinetic properties of the rabbit gastric lipase. Biochimicaet Biophysica Acta 1988; 960 : 286-23.

Mortensen BK Production of yellow fats and spreads. In: Tamime AY, ed. Dairy fats and related products. 2009.

Mortensen LS, Hartvigsen ML, Brader LJ, et al. Differential effects of protein quality on postprandial lipemia in response to a fat-rich meal in type 2 diabetes: comparison of whey, casein, gluten, and cod protein. Am J Clin Nutr 2009 ; $90: 41-48$.

Mortimer BC, Holthouse DJ, Martins IJ, Stick RV, Redgrave TG. Effects of triacylglycerol-saturated acyl chains on the clearance of chylomicron-like emulsions from the plasma of the rat. Biochim Biophys Acta 1994 ; 1211 : 171-80.

$\mathrm{Mu} \mathrm{H}$, Høy CE. Intestinal absorption of specific structured triacylglycerols. J Lipid Res $2001 ; 42: 792-8$.

$\mathrm{Mu} \mathrm{H}$, Hoy CE. The digestion of dietary triacylglycerols. Prog Lipid Res 2004; 43 : 105-33.

$\mathrm{Mu} \mathrm{H}$, Porsgaard T. The metabolism of structured triacylglycerols. Prog Lipid Res $2005 ; 44: 430-48$.

Muchow M, Maincent P, Muller RH. Lipid nanoparticles with a solid matrix (SLN, NLC, LDC) for oral drug delivery. Drug Dev Ind Pharm 2008 ; 34 : 1394-405.

Muchow M, Schmitz El, Despatova N, Maincent $\mathrm{P}$, Muller RH. Omega-3 fatty acids-loaded lipid nanoparticles for patientconvenient oral bioavailability enhancement. Pharmazie 2009 ; 64 : 499-504.

Muller RH, Keck CM. Challenges and solutions for the delivery of biotech drugs-a review of drug nanocrystal technology and lipid nanoparticles. J Biotechnol 2004 ; 113 : 151-70.

Mun S, Decker E, McClements D. Influence of emulsifier type on in vitro digestibility of lipid droplets by pancreatic lipase. Food Res Int $2007 ; 40: 770-81$.

Nagata J, Kasai M, Watanabe S, Ikeda I, Saito M. Effects of highly purified structured lipids containing medium-chain fatty acids and linoleic acid on lipid profiles in rats. Biosci Biotechnol Biochem 2003 ; 67 : 1937-43.

Nelson SE, Rogers RR, Frantz JA, Ziegler EE. Palm olein in infant formula: absorption of fat and minerals by normal infants. Am J Clin Nutr 1996 ; $64: 291-6$.

Nestel PJ, Noakes M, Belling GB, McArthur R, Clifton PM. Effect on plasma lipids of interesterifying a mix of edible oils. Am / Clin Nutr $1995 ; 62$ : 950-5.

Nishimukai M, Hara H, Aoyama Y. Enteral administration of soybean lecithin enhanced lymphatic absorption of triacylglycerol in rats. Brit J Nutr 2003; 90 : 565-51.

Nishimukai M, Hara H. Soybean phosphatidylcholine-induced enhancement of lymphatic absorption of triglyceride depends on chylomicron formation in rats. Biosci Biotech Bioch 2007 ; 71 : 1192-7.

Nordoy A, Barstad L, Connor WE, Hatcher L. Absorption of the n-3 eicosapentaenoic and docosahexaenoic acids as ethyl esters and triglycerides by humans. Am J Clin Nutr 1991 ; 53 : 1185-90.

Norton I, Moore S, Fryer P. Understanding food structuring and breakdown: engineering approaches to obesity. Obes $\operatorname{Rev} 2007$; $8:$ : $883-8$

Norum KR, Helgerud P, Petersen LB, Groot $\mathrm{PH}$, De Jonge HR. Influence of diets on acylCoA : cholesterol acyltransferase and on acylCoA : retinol acyltransferase in villous and crypt cells from rat small intestinal mucosa and in the liver. Biochim Biophys Acta 1983 ; 751 : 153-61.

Olbrich C, Kayser O, Muller RH. Lipase degradation of Dynasan 114 and 116 solid lipid nanoparticles (SLN)-effect of surfactants, storage time and crystallinity. Int J Pharm 2002 ; 237 : 119-28.

Ollivon M, Perron R. Propriétés physiques des corps gras. In: KA, JP Wolff, JF Guttmann (Eds), Manuel des corps gras. Paris : Lavoisier, 1992 : 433-42.

Ollivon M, Keller G, Bourgaux C, Kalnin D, Villeneuve $P$, Lesieur $P$. DSC and high resolution X-ray diffraction coupling. I Thermal Anal Calorim 2006 ; 85 : 219-24.

Osborn HT, Akoh CC (2002). Structured lipids-novel fats with medical, nutraceutical, and food applications. Comp Rev Food Sci $F$ $2002 ; 1$ : 93-103.

Palanuwech J, Coupland J. Effect of surfactant type on the stability of oil-in-water emulsions to dispersed phase crystallization. Colloids and Surfaces A: Physicochem Eng Aspects $2003 ; 223: 251-62$.

Papakonstantinou E, Flatt WP, Huth PJ, Harris RB. High dietary calcium reduces body fat content, digestibility of fat, and serum vitamin D in rats. Obes Res 2003; 11 : 387-94.

Pasquier B, Armand M., Castelain C, et al. Emulsification and lipolysis of triacylglycerols are altered by viscous soluble dietary fibres in acidic gastric medium in vitro. Biochem J 1996 ; $314: 269-75$.
Payet M, Esmail MH, Polichetti E, et al. Docosahexaenoic acid-enriched egg consumption induces accretion of arachidonic acid in erythrocytes of elderly patients. $\mathrm{Br}$ J Nutr $2004 ; 91$ : 789-96.

Peltier S, Oger JM, Lagarce F, Couet W, Benoit JP. Enhanced oral paclitaxel bioavailability after administration of paclitaxelloaded lipid nanocapsules. Pharm Res 2006 ; 23 : 1243-50.

Pieroni G, Coste TC. Composition en acides gras des œufs : intérêt nutritionnel et valeur santé. Oléagineux, Corps Gras, Lipides 2010 ; $17: 43-6$.

Pople PV, Singh KK. Development and evaluation of topical formulation containing solid lipid nanoparticles of vitamin A. AAPS Pharm Sci Tech 2006; 7 : 91.

Porsgaard T, Hoy CE. Lymphatic transport in rats of several dietary fats differing in fatty acid profile and triacylglycerol structure. I Nutr $2000 ; 130$ : 1619-24.

Porsgaard T, Xu X, Göttsche J, Mu H. Differences in the intramolecular structure of structured oils do not affect pancreatic lipase activity in vitro or the absorption by rats of (n-3) fatty acids. J Nutr 2005 ; 135 : 1705-11.

Raatz SK, Redmon JB, Wimmergren N, Donadio JV, Bibus DM. Enhanced absorption of n-3 fatty acids from emulsified compared with encapsulated fish oil. / Am Diet Assoc 2009 ; 109 : 1076-81.

Ramirez M, Amate L, Gil A. Absorption and distribution of dietary fatty acids from different sources. Early Hum Dev 2001 ; 65 : S95-S101.

Redgrave TG, Kodali DR, Small DM. The effect of triacyl-sn-glycerol structure on the metabolism of chylomicrons and triacylglycerol-rich emulsions in the rat. / Biol Chem 1988 ; $263: 5118-23$.

Renaud SC, Ruf JC, Petithory D. The positional distribution of fatty acids in palm oil and lard influences their biologic effects in rats. J Nutr $1995 ; 125$ : 229-37.

Ribaya-Mercado JD. Influence of dietary fat on beta-carotene absorption and bioconversion into vitamin A. Nutr Rev 2002 ; 60 :104-10.

Robinson DM, Martin NC, Robinson LE, Ahmadi L, Marangoni AG, Wright A. J. Influence of interesterification of a stearic acid-rich spreadable fat on acute metabolic risk factors. Lipids $2009 ; 44$ : 17-26.

Roodenburg AJ, Leenen R, Van Het Hof KH, Weststrate JA, Tijburg LB. Amount of fat in the diet affects bioavailability of lutein esters but not of alpha-carotene, beta-carotene, and vitamin E in humans. Am J Clin Nutr 2000 ; 71 : 1187-93.

Rousseau D. Fat crystals and emulsion stability a review. Food Res Int $2000 ; 33$ : 3-14. 
Rudkowska I, Roynette CE, Demonty I, Vanstone CA, Jew S, Jones PJ. Diacylglycerol: efficacy and mechanism of action of an antiobesity agent. Obes Res $2005 ; 13$ : 1864-76.

Saito S, Tomonobu K, Hase T, Tokimitsu I. Effects of diacylglycerol on postprandial energy expenditure and respiratory quotient in healthy subjects. Nutrition $2006 ; 22: 30-5$.

Sala-Vila A, Castellote Al, Campoy C, Rivero $M$, Rodriguez-Palmero $M$, Lopez-Sabater MC. The source of long-chain PUFA in formula supplements does not affect the fatty acid composition of plasma lipids in fullterm infants. J Nutr 2004 ; 134 : 868-73.

Sala-Vila A, Castellote Al, Lopez-Sabater MC. The intramolecular position of docosahexaenoic acid in the triacylglycerol sources used for pediatric nutrition has a minimal effect on its metabolic use. Nutr Res 2008 ; $28: 131-6$.

Sanders TA, Berry SE, Miller GJ. Influence of triacylglycerol structure on the postprandial response of factor VII to stearic acid-rich fats. Am J Clin Nutr 2003 ; 77 : 777-82.

Sanders TA, Oakley FR, Cooper JA, Miller GJ. Influence of a stearic acid-rich structured triacylglycerol on postprandial lipemia, factor VII concentrations, and fibrinolytic activity in healthy subjects. Am / Clin Nutr 2001; 73 : 715-21.

Sanggaard KM, Holst JJ, Rehfeld JF, Sandstrom B, Raben A, Tholstrup T. Different effects of whole milk and a fermented milk with the same fat and lactose content on gastric emptying and postprandial lipaemia, but not on glycaemic response and appetite. Br J Nutr $2004 ; 92$ : 447-59.

Sarda L, Desnuelle P. Actions of pancreatic lipase on esters in emulsions. Biochimica et Biophysica Acta 1958 ; 30 : 513-21.

Sarmento B, Martins S, Ferreira D, Souto EB. Oral insulin delivery by means of solid lipid nanoparticles. Int / Nanomedicine 2007 ; 2 : 743-9.

Sato K, Ueno S, Yano J. Molecular interactions and kinetic properties of fats. Prog Lipid Res $1999 ; 38: 91-116$.

Scanu A. Serum high-density lipoprotein: effect of change in structure on activity of chicken adipose tissue lipase. Science 1966 ; $153: 640-1$.

Schreiner M, Hulan HW, Razzazi-Fazeli E, Bohm J, Iben C.Feeding laying hens seal blubber oil: effects on egg yolk incorporation, stereospecific distribution of omega- 3 fatty acids, and sensory aspects. Poult Sci 2004; $83: 462-73$.

Schurgers LJ, Shearer MJ, Soute BA, et al. Novel effects of diets enriched with corn oil or with an olive oil/sunflower oil mixture on vitamin $\mathrm{K}$ metabolism and vitamin $\mathrm{K}$-depen- dent proteins in young men. J Lipid Res 2002 ; 43 : 878-84.

Schweigert FJ, Baumane A, Buchholz I, Schoon HA. Plasma and tissue concentrations of beta-carotene and vitamin A in rats fed beta-carotene in various fats of plant and animal origin. J Environ Pathol Toxicol Oncol $2000 ; 19: 87-93$.

Shahkhalili Y, Murset C, Meirim I, et al. Calcium supplementation of chocolate: effect on cocoa butter digestibility and blood lipids in humans. Am / Clin Nutr $2001 ; 73: 246-52$.

Shidhaye SS, Vaidya R, Sutar S, Patwardhan A, Kadam VJ. Solid lipid nanoparticles and nanostructured lipid carriers-innovative generations of solid lipid carriers. Curr Drug Deliv 2008 ; 5 : 324-31.

Singh $\mathrm{H}, \mathrm{Ye} \mathrm{A}$, Horne D. Structuring food emulsions in the gastrointestinal tract to modify lipid digestion. Prog Lipid Res 2009 ; 48 : 92-100.

Sirvente H, Beaumal V, Gaillard C, Bialek L, Hamm D, Anton M. Structuring and functionalization of dispersions containing egg yolk, plasma and granules induced by mechanical treatments. J Agric Food Chem 2007 ; 55 : 9537-44.

Small DM. The effects of glyceride structure on absorption and metabolism. Annu Rev Nutr 1991 ; 11 : 413-34.

Softly B, Huang A, Finley J, et al. Composition of representative SALATRIM fat preparations: A potential low-calorie fat substitute. I Agric Food Chem 1994 ; 42 : 461-7.

Song JH, Miyazawa T. Superior oxidative stability of docosahexaenoic acid-enriched oils in the form of phospholipids. J Food Lipids 1997 ; 4 : 109-17.

Spitsberg VL. Invited review: Bovine milk fat globule membrane as a potential nutraceutical. J Dairy Sci 2005 ; 88 : 2289-94.

Straarup EM, Høy CE. Lymphatic transport of fat in rats with normal- and malabsorption following intake of fats made from fish oil and decanoic acid. Effects of triacylglycerol structure. Nutr Res $2001 ; 21$ : 1001-13.

Straarup EM, Lauritzen L, Faerk J, Hoy, Deceased CE, Michaelsen KF. The stereospecific triacylglycerol structures and Fatty Acid profiles of human milk and infant formulas. I Pediatr Gastroenterol Nutr 2006 ; 42 : 293-9.

Summers LK, Fielding BA, Herd CL, et al. Use of structured triacylglycerols containing predominantly stearic and oleic acids to probe early events in metabolic processing of dietary fat. / Lipid Res 1999 ; 40 : 1890-8.

Summers LK, Fielding BA, Ilic V, Quinlan PT, Frayn $\mathrm{KN}$. The effect of triacylglycerol-fatty acid positional distribution on postprandial metabolism in subcutaneous adipose tissue. Br J Nutr 1998 ; 79 : 141-7.

Svenstrup G, Brüggemann D, Kristensen L, Risbo J, Skibste L. The influence of pretreatment on pork fat crystallization. Eur J Lipid Sci Technol $2005 ; 107$ : 607-15.

Taguchi $\mathrm{H}$, Watanabe $\mathrm{H}$, Onizawa $\mathrm{K}$, et al. Double-blind controlled study on the effects of dietary diacylglycerol on postprandial serum and chylomicron triacylglycerol responses in healthy humans. I Am Coll Nutr 2000 ; 19 : 789-96.

Takahashi M, Uechi S, Takara K, Asikin Y, Wada K. Evaluation of an oral carrier system in rats: bioavailability and antioxidant properties of liposome-encapsulated curcumin. J Agric Food Chem 2009 ; 57 : 9141-6.

Takase H. Metabolism of diacylglycerol in humans. Asia Pac J Clin Nutr 2007 ; 16 : S398-403.

Takenaka A, Hosokawa M, Miyashita K. Unsaturated phosphatidylethanolamine as effective synergist in combination with $\alpha$ tocopherol, 2007. J Oleo Sci 2007 ; 56 : 511-6.

Tamai T, Murota I, Maruyama K, et al. Effects of supplemented diacylglycerol rich in docosahexaenoic acid on serum triacylglycerol in a diet-induced hyperlipidemic model of rats are essentially equivalent to those of triacylglycerol rich in docosahexaenoic acid. Biol Pharm Bull 2007 ; 30 : 2381-8.

Tardieu C, Chaté V, Guzun R, et al. Loss of body mass and exercise endurance under hypoxic conditions is reduced with glycerophospholipids enriched in docosahexaenoic acid (GPL-DHA) supplementation in rodents. Clin Nutr 2009 ; S4 : 6.

Thies F, Delachambre MC, Bentejac M, Lagarde M, Lecerf J. Unsaturated fatty acids esterified in 2-acyl-I-lysophosphatidylcholine bound to albumin are more efficiently taken up by the young rat brain than the unesterified form. J Neurochem 1992 ; 59 : 1110-6.

Tholstrup T, Hoy CE, Andersen LN, Christensen RD, Sandstrom B. Does fat in milk, butter and cheese affect blood lipids and cholesterol differently? J Am Coll Nutr 2004 ; 23 : 169-76.

Thompson AK, Singh $\mathrm{H}$. Preparation of liposomes from milk fat globule membrane phospholipids using a microfluidizer. I Dairy Sci 2006 ; 89 : 410-9.

Torchilin VP. Recent advances with liposomes as pharmaceutical carriers. Nat Rev Drug Discov $2005 ; 4$ : 145-60.

Toro-Vazquez J, Rangel-Vargas E, DibildoxAlvarado E, Charó-Alonso M. Crystallization of cocoa butter with and without polar lipids evaluated by rheometry, calorimetry and polarized light microscopy. Eur J Lipid Sci Technol $2005 ; 107: 641-55$. 
Tou JC, Jaczynski J, Chen YC. Krill for human consumption: nutritional value and potential health benefits. Nutr Rev 2007; 65 : 63-77.

Trotter PJ, Storch J. Nutritional control of fatty acid esterification in differentiating Caco-2 intestinal cells is mediated by cellular diacylglycerol concentrations. J Nutr $1993 ; 123$ : 728-36.

Tuomasjukka SS, Viitanen MH, Kallio HP. Regio-distribution of stearic acid is not conserved in chylomicrons after ingestion of randomised, stearic acid-rich fat in a single meal. J Nutr Biochem 2009 ; 20 : 909-15.

Valenzuela A, Valenzuela V, Sanhueza J, Nieto $S$. Effect of supplementation with docosahexaenoic acid ethyl ester and sn-2 docosahexaenyl monoacylglyceride on plasma and erythrocyte fatty acids in rats. Ann Nutr Metab 2005 ; 49 : 49-53.

Van Den Berg H. Bioavailability of vitamin D. Eur J Clin Nutr 1997 ; 51 : S76-9.

Visioli F, Rise P, Barassi MC, Marangoni F, Galli C. Dietary intake of fish vs. formulations leads to higher plasma concentrations of $n-3$ fatty acids. Lipids $2003 ; 38: 415-8$.

Wallace JM, Mccabe AJ, Robson PJ, et al. Bioavailability of $n-3$ polyunsaturated fatty acids (PUFA) in foods enriched with microencapsulated fish oil. Ann Nutr Metab 2000 ; 44 : 157-62.

Walstra P. Physical Chemistry of Foods. New York : $2003: 807$.

Wang J, Shahidi F. Effect of enzymatic randomization on positional distribution and stability of seal blubber and menhaden oils. J Agric Food Chem 2011 ; 59 : 4232-7.

Ward RE, German JB, Corredig M. Composition, applications, fractionation, technological and nutritional significance of milk fat globule membrane material. In : Fox and McSweeney (Eds), Advanced Dairy Chemistry. 2. Lipids. New York (USA), $2006: 213-44$.

Wat E, Tandy S, Kapera E, et al. Dietary phospholipid-rich dairy milk extract reduces hepatomegaly, hepatic steatosis and hyperlipidemia in mice fed a high-fat diet. Atherosclerosis 2009 ; 205 : 144-50.

Wawrezinieck A, Pean JM, Wuthrich P, Benoit JP. Oral bioavailability and drug/carrier particulate systems. Med Sci (Paris) 2008; 24 : 659-64.

Werner A, Havinga R, Kuipers F, Verkade HJ. Treatment of EFA deficiency with dietary triglycerides or phospholipids in a murine model of extrahepatic cholestasis. Am J Physiol Gastrointest Liver Physiol 2004; 286 : G822-32.

Westphal S, Kastner S, Taneva E, Leodolter A, Dierkes J, Luley C. Postprandial lipid and carbohydrate responses after the ingestion of a casein-enriched mixed meal. Am J Clin Nutr $2004 ; 80$ : 284-90.

Westphal S, Leodolter A, Kahl S, Dierkes J, Malfertheiner P, Luley C. Addition of glucose to a fatty meal delays chylomicrons and suppresses VLDL in healthy subjects. Eur J Clin Invest $2002 ; 32$ : 322-7.

Whitcomb DC, Lowe ME. Human pancreatic digestive enzymes. Dig Dis Sci 2007; 52 : 1-17.

Wijendran V, Huang MC, Diau GY, Boehm G, Nathanielsz PW, Brenna JT. Efficacy of dietary arachidonic acid provided as triglyceride or phospholipid as substrates for brain arachidonic acid accretion in baboon neonates. Pediatr Res 2002 ; 51 : 265-72.

Wilton DC. In : DE Vance, JE Vance (Eds), Phospholipases, 5e édition, $2008: 653$.
Wood JD, Enser M, Fisher AV, et al. Fat deposition, fatty acid composition and meat quality: A review. Meat Sci 2008; $78: 343-58$.

Yamamoto K, Takeshita M, Tokimitsu I, et al. Diacylglycerol oil ingestion in type 2 diabetic patients with hypertriglyceridemia. Nutrition $2006 ; 22: 23-9$.

Yang LY, Kuksis A. Apparent convergence (at 2-monoacylglycerol level) of phosphatidic acid and 2-monoacylglycerol pathways of synthesis of chylomicron triacylglycerols. J Lipid Res 1991 ; 32 : 1173-86.

Yilmaz G, Jongboom R, Feil H, Hennink W. Encapsulation of sunflower oil in starch matrices via extrusion: effect of the interfacial properties and processing conditions on the formation of dispersed phase morphologies. Carbohydrate Polymers 2001 ; $45:$ 403-10.

Yli-Jokipii KM, Schwab US, Tahvonen RL, Kurvinen JP, Mykkanen HM, Kallio HPT. Chylomicron and VLDL TAG structures and postprandial lipid response induced by lard and modified lard. Lipids $2003 ; 38$ : 693-703.

Yli-Jokipii K, Kallio H, Schwab U, et al. Effects of palm oil and transesterified palm oil on chylomicron and VLDL triacylglycerol structures and postprandial lipid response. J Lipid Res 2001 ; 42 : 1618-25.

Zampelas A, Williams CM, Morgan LM, Wright J, Quinlan PT. The effect of triacylglycerol fatty acid positional distribution on postprandial plasma metabolite and hormone responses in normal adult men. $\mathrm{Br} J$ Nutr 1994 ; 71 : 401-10.

Zock PL, De Vries JH, De Fouw NJ, Katan MB. Positional distribution of fatty acids in dietary triglycerides: effects on fasting blood lipoprotein concentrations in humans. Am / Clin Nutr $1995 ; 61: 48-55$. 